\title{
Does Election Salience Affect Immigrant Voter Turnout?*
}

\author{
Linuz Aggeborn \\ Henrik Andersson \\ Sirus Håfström Dehdari Karl-Oskar Lindgren
}

May 28, 2020

\begin{abstract}
Faced with rising levels of cross-border migration, many democratic countries have extended local voting rights to non-naturalized immigrants in recent decades. However, the low turnout of enfranchised immigrants in these elections has come as a disappointment to the advocates of such reforms. In this study, we examine whether the low turnout can be explained by the low salience of local elections. Based on a regression discontinuity design and using high-quality Swedish registry data, we find this to be the case. According to our results, the average likelihood of voting increases by $10-20$ percentage points once immigrants become eligible to vote in national elections. We demonstrate too that this effect is not driven by the acquisition of citizenship per se, and that the individual characteristics of immigrants cannot explain their overall lower rate of voter turnout.
\end{abstract}

Keywords: Voter turnout; Election salience; Sweden; Immigrants; RDD

\footnotetext{
*The authors are affiliated with the Department of Government, Uppsala University (LA, HA, SHD, and KOL), the Uppsala Center for Labor Studies (LA, HA, and KOL), the Uppsala Center for Fiscal Studies (LA and HA), the Institute for Social Research (SOFI) at Stockholm University (SHD), and the Institute for Evaluation of Labour Market and Education Policy (KOL). Corresponding author's address: Linuz Aggeborn, Box 514, 75120 Uppsala, Sweden. E-mail: linuz.aggeborn@statsvet.uu.se. The authors are thankful to seminar participants at Uppsala University, to participants at the 1st immigration lab meeting in Uppsala, and to seminar participants at APSA 2019 in Washington D.C. The authors gratefully acknowledge financial support from the European Research Council, grant number 683214 CONPOL, and from the Swedish Research Council, grant number 2017-00764.
} 


\section{Introduction}

Over recent decades, many developed democracies have seen an increase in the share of foreign-born residents. The fact that many of these immigrants lack citizenship in their new host countries poses an important challenge to the functioning and legitimacy of representative democracy. If voting rights are tied to citizenship, a large part of the population will lack the opportunity to affect political decisions in the country where they live.

In response to this, an increasing number of democratic countries have decided to extend voting rights in sub-national elections to non-citizen residents (Ferris et al. 2019). However, as scholars have noted, voter turnout among non-naturalized immigrants typically falls short of the expectations of advocates of these reforms (Ruedin 2018; Seidle 2015; Togeby 1999). A striking example of this can be seen in Sweden, which was the first European country to grant voting rights to non-citizens (in 1976). In Sweden, more than 80 percent of natives have voted in recent municipal elections, but only 35 percent of eligible non-citizens have done so (Bevelander 2015). ${ }^{1}$ Why is it, then, that many non-naturalized immigrants choose not to vote even when they are entitled to do so?

One way to attempt to answer this question is to turn to the more general research on the political participation of immigrants (de Rooij 2012). In this literature, scholars have examined whether the lower turnout for immigrants than for natives can be attributed to demographic and socio-economic differences between the two groups (Bevelander and Pendakur 2011; Wass et al. 2015), as

\footnotetext{
${ }^{1}$ Note that the term "natives" in this study refers to individuals born in Sweden, and "immigrants" to those living in Sweden but who are born abroad.
} 
well as to differences which are harder to measure - such as political skills, interest, and efficacy (Ruedin 2018).

One feature common to all of these explanations is that they focus on the characteristics of individuals. Immigrants are believed to vote to a lesser extent because they differ from the native population in important respects. However, as Franklin et al. (2004) forcefully argue, turnout is not only a matter of people or of societies; it is also a matter of elections. Most importantly, turnout can be expected to be higher in elections where issues of vital concern are at stake. Low voter turnout should therefore "be blamed on the character of the election, not on the characters of those who failed to vote" (Franklin et al. 2004, p.2).

Viewed from this perspective, we would expect non-naturalized immigrants to be more likely to engage in the politics of their host countries if they also have the right to vote in national elections, where the political stakes are higher. But is this really the case? Or is the comparatively low turnout of eligible foreign citizens mostly due to individual immigrant characteristics? The present study attempts to answer these central questions.

However, having posed this research problem, we are faced with the challenge of how to establish a causal link between election salience and immigrant turnout. Two possibilities immediately come to mind. First, we can compare immigrant turnout in the few countries (such as New Zealand) where non-naturalized immigrants can vote in national elections to turnout in countries where they can only vote in local elections. Second, we can compare the turnout of naturalized immigrants with that of non-naturalized immigrants within particular countries.

Both of these research designs are likely to suffer from omitted variables bias. In the first case, there may be unmeasured factors affecting both (a) the initial 
decision to allow foreign citizens to vote in national elections, and (b) the subsequent turnout of this group. In the second case, immigrants who choose to naturalize may differ systematically from those who do not.

In this study, therefore, we resort to a different empirical strategy. We take advantage of the fact that local and national elections in Sweden are held on the same day. Whereas immigrants who are citizens can vote in both elections, non-naturalized immigrants can only vote in the local one. To examine how the opportunity to vote in the national election affects immigrant turnout, we can thus use a regression discontinuity design (RDD) to compare the turnout among immigrants who have acquired citizenship around the time of the election.

Yet, it could still be difficult to tell whether an observed difference in voter turnout between naturalized and non-naturalized immigrants is due to national voting eligibility or to naturalization per se. An individual that becomes a citizen acquires the right to vote, but he or she also becomes part of an electorate for which voter turnout is generally higher. This may furthermore result in a general sensation of belonging to the national context of the new country. To make progress on the issue of disentangling the two treatments from each other, we utilize the fact that immigrants who naturalize on a date too close to election day are not eligible to vote in the national election. This means that, in any given election year, there are individuals who are citizens but who lack the right to vote in national elections.

Thus, one important reason for situating the study in the Swedish context lies in the existence of certain institutional features that facilitate the empirical analysis, such as a common election day for local and national elections, and a requirement that immigrants naturalize in sufficient advance of the election in 
order to gain full voting rights. Another reason lies in the availability of validated population-wide data on turnout in conjunction with detailed individual-level information from various administrative registers. We leverage these data in order to study the relationship between election salience and immigrant turnout.

Previewing our findings, we can say that the results indicate that the salience of an election has an important effect on immigrant turnout. On average, immigrants who are allowed to vote in the national election are 10-20 percentage points more likely to take part in the local election as well. Furthermore, we present results showing that voter turnout in local elections does not increase among immigrants who have obtained citizenship too close to the election to be eligible to vote in the national election. This indicates that the increase in turnout is due to election salience, rather than to citizenship per se. Lastly, our findings suggest that socio-economic and demographic characteristics cannot explain the gap in voter turnout between natives and immigrants. Taken all together, these results point to the conclusion that it is election salience, and not those other factors, that primarily explains the lower voter turnout among immigrants. We find support, then, for the view that extending voting rights at the national level to non-citizen residents could help further their political incorporation.

\section{Theory and previous research}

In most democracies historically, voting eligibility has been reserved for citizens. Immigrants have therefore had to naturalize in order to take part in their host country's elections. Recently this has started to change, as an increasing number of democracies have extended voting rights in local elections to non-naturalized 
immigrants (Ferris et al. 2019). However, as mentioned in the introduction, the relatively low voter turnout of enfranchised immigrants has come as an unwelcome surprise to many of the advocates of these reforms. Accordingly, the Swiss politician interviewed by Didier Ruedin is not alone in wondering: why do non-naturalized immigrants not vote, "now that we have given them the opportunity?" (Ruedin 2018, p.243).

It is natural that, in seeking to answer this vital question, we turn to the voluminous research on political participation in general, and on voting in particular. Traditionally, this literature has been dominated by three broad theories. One focuses on individual resources, another on the importance of socialization and mobilization, and a third on the impact of the institutional context (Franklin 1996). All three theories might be able to help explain the low voter turnout of non-naturalized immigrants.

According to the first type of explanation, the comparatively low voter turnout among non-naturalized immigrants can be attributed, at least in part, to various demographic factors and to an overall lack of socio-economic resources. This resource theory holds that people participate politically to the extent they have the skills, money, and time to do so (e.g., Verba and Nie 1972). Compared to both natives and naturalized immigrants, non-naturalized immigrants tend to be younger, to have less education, and to receive lower incomes. These factors should contribute to their lower voter turnout, according to the theory in question.

A second strand of the literature instead highlights the role played by political socialization and mobilization. The basic idea here is that people are more likely to take part in politics when they are encouraged to do so (e.g., Rosenstone and Hansen 1993). A particularly important source of such encouragement is that 
received from parents and other adults during childhood and early adolescence. One reason for the low turnout among immigrants that has been proposed in the literature, therefore, is that many immigrants have been raised in autocratic countries, making them less likely to have been socialized into voting at an early age (Ruedin 2018; Wass et al. 2015). A closely related argument instead stresses the encouragement from social networks later in life (Campbell 2013). Viewed from this perspective, an important reason for the voting gap between natives and immigrants is that natives typically have access to politically more active social networks, helping to boost their political engagement (de Rooij 2012; Gidengil and Stolle 2009; Ruedin 2018).

However, the results from previous empirical studies on the importance of resources and of mobilization are somewhat mixed. Some have found that differences in demographic and socio-economic factors explain most of the majority-minority gap in voting (Adman and Strömblad 2000; Verba et al. 1993). Others maintain that the resource model performs very poorly in predicting voter turnout among minority groups (Heath et al. 2011). A couple of studies come out in between: according to these, resources and mobilization account for some of the variation in voter turnout, but far from all of it (Bevelander and Pendakur 2011; Ruedin 2018; Wass et al. 2015).

A third group of scholars, finally, claims the institutional context is usually more important than either individual resources or social networks in explaining voter turnout (e.g., Franklin et al. 2004). The list of institutional features discussed in the literature is long, and includes such things as compulsory-voting laws, party and electoral systems, and the competitiveness and salience of different 
elections (Blais 2000). ${ }^{2}$

At first sight, it may appear unlikely that such contextual features can help explain the differences in voter turnout between natives and immigrants. Both groups, namely, face the same set of institutions. It may be, however, that particular institutions affect natives and immigrants differently. Yet more important is the fact that, even in the countries that have granted voting rights to non-citizens, there is usually at least one institutional factor that could help account for the low voter turnout among non-naturalized immigrants. Unlike natives or naturalized immigrants, that is to say, non-naturalized immigrants can typically only vote in local elections. And in most countries, local and regional elections are considered less important than national ones (e.g., Cancela and Geys 2016).

Thus, as for instance Hammar (1979) and Öhrvall (2006) has suggested, the lower salience of local elections may be important for explaining why so many non-naturalized immigrants abstain from voting even when they are eligible. That is, many immigrants may not find it worthwhile to vote since they cannot vote in the election that matters the most. Or, as one Swedish public official recently put it when commenting on the decision to introduce local voting rights for non-nationals in Sweden:

"[T]his was a progressive step at the time they were introduced; however, now it is almost an 'insult' because of the widespread

\footnotetext{
${ }^{2}$ Engdahl, Lindgren, and Rosenqvist 2020 found that the incidence of naturalization and voting in the future were not affected by gaining the right to vote in local elections earlier, rather than later, after immigrating to Sweden.
} 
perception among immigrants that native-born Swedes 'don't care' [about local elections]" (Seidle 2015, p. 33).

This raises the interesting question of how much higher turnout would be if non-naturalized immigrants were also allowed to vote in national elections. Although we are not aware of any well-identified studies that have examined this issue specifically, the question is closely related to the research on the impact of concurrent elections on turnout (e.g., Geys 2006). A key finding of these studies, which have employed both difference-in-difference and regression discontinuity designs, is that voter turnout in second-order elections, such as local elections, tends to increase substantially when they are held at the same time as first-order elections, such as national ones (e.g., Aggeborn 2016; Garmann 2016; Hajnal and Lewis 2003; Leininger, Rudolph, and Zittlau 2018).

This has often been interpreted as a salience effect: i.e., voters are more likely to vote in national elections because they are considered more important and receive better media coverage than local ones. Higher salience may in turn reduce the information costs associated with voting, as well as making it more likely that individual citizens will consider it a civic duty to vote (Garmann 2016).

In this study, we ask whether this logic also applies to immigrants. To the extent this is the case, non-naturalized immigrants can be expected to vote to a greater extent if they are eligible to vote not just in local elections but in national ones as well. One indication this may be the case is that some studies show that the turnout gap between natives and immigrants decreases substantially once citizenship is controlled for (Bevelander and Pendakur 2011; Öhrvall 2006). That is, immigrants who have acquired citizenship and have the right to vote in 
national elections are much more likely to vote than are non-naturalized immigrants, who can only vote in local elections.

At least two difficulties arise, however, when we try to interpret the results from these citizenship studies. First, based on the type of design used in these previous studies, it is not possible to rule out the possibility that the differences in voter turnout between naturalized and non-naturalized immigrants are due to other (unobserved) differences between the two groups. Second, even if we could be assured that naturalized and non-naturalized immigrants are identical in all relevant regards, we would still face the problem of understanding why it is that immigrants become more likely to vote once they acquire citizenship. One possibility, obviously, is that citizens become more likely to vote because they are eligible to vote in national elections. However, an alternative explanation would be that naturalization in itself has an effect on voter turnout, because immigrants become more committed to their host country and their new national context when they gain citizenship (Bevelander 2015). We attempt in this study to address both of these challenges, which to our knowledge has not been done before.

\section{Institutional Setting}

Local and national elections are held in Sweden on the same day, once every fourth year. Local elections do carry substantive weight, as both municipalities and counties have taxation rights and are important providers of public services. Yet it is the national election that usually constitutes the main focus of party campaigns and of media coverage. In this sense local elections, although important in their potential policy impact, have the character of second-order 
elections (Oscarsson 2001). Throughout the paper, we are going to define voting in local election as voting in either the municipal election or the county election.

Non-citizen residents were granted voting rights at the local level in 1976. Since then, non-citizens have been eligible to vote in such elections provided they have resided in Sweden for at least three years directly prior to the elections. To be eligible to vote in the national election, on the other hand, immigrants must hold Swedish citizenship.

In order for an adult to become a citizen, immigrants must meet the following four criteria: i) they must be at least 18 years old; ii) they must have a permanent residence permit; iii) they must have resided in Sweden for at least five years; ${ }^{3}$ and $i v$ ) they must fulfill a requirement of good conduct (Engdahl 2014, p. 9). An individual who meets all four of these prerequisites can apply for citizenship at the Swedish Migration Agency, which handles all applications. In those cases where the Migration Agency decides to grant citizenship, it sends a letter to the Swedish Tax Agency to inform it of this decision. Then, after some unspecified processing time, the Tax Agency records the change in citizenship status in the population registers. The Elections Agency, which is responsible for putting electoral rolls together, only considers an individual to be a citizen (and hence eligible to vote in national elections) if said individual is registered as a citizen in the population registers. The waiting time before a citizenship decision is taken can be long. The average waiting time currently is around three years. ${ }^{4}$

All individuals who become Swedish citizens in time to be registered on the

\footnotetext{
${ }^{3}$ For refugees this requirement is four years, and for those cohabiting with a Swedish citizen it is only three years.

${ }^{4}$ See Migrationsverket (2020).
} 
electoral rolls are eligible to vote in elections to the national parliament. Nowadays, this means an individual must be recorded as a citizen in the population registers no later than 30 days before the election. Prior to 1998, this administrative period was somewhat longer. To be registered on the electoral rolls then, immigrants had to be recorded as Swedish citizens by the Tax Agency prior to the 1st of July: i.e., about two and a half months before the upcoming election.

Individuals do not have to register to vote in Sweden; rather, all eligible individuals receive a voting-rights certificate by mail three to four weeks before election day. This certificate contains basic information about the election, such as time and place, and specifies the elections in which the individual in question is eligible to vote. It thus behooves those who gain citizenship too close to election day to be registered on the electoral rolls to be aware of this fact well in advance of the election.

Lastly, before moving on to the empirical part of this paper, we should set the context with a few basic facts on the sub-population in which we take an interest here: immigrants in Sweden. The proportion of foreign-born persons in Sweden is among the highest in Europe. The approximately 2 million foreign-born individuals make up about $19 \%$ of the population, compared to less than $3 \%$ in 1950. The increase stems from Nordic and other European labor migration during the 1950's and 1960's, and refugee and family-related migration from non-European countries in the 1980's up until now. These historical trends are similar to those found in many other countries of Western Europe. Note too that many of the foreign-born individuals are non-citizens. At the end of 2018, about 9 percent of the Swedish population consisted of foreign citizens. We may conclude, therefore, that a sizable fraction of the Swedish population is affected by the 
factors noted in this study.

\section{Measurements and Method}

We proceed now to our empirical framework, beginning with a description of the data material. We turn then to our identification strategy and to a description of how we estimate the effect of election salience on the our main analysis.

\section{Data}

This study makes use of full population data from two different sources. First, we have obtained information on a wide range of individual-level variables from administrative registers maintained by Statistics Sweden. Most importantly, these data contain complete records of dates for immigration and naturalization, which are both key to our research design. We also have access to detailed information on various demographic and socio-economic characteristics, such as age, gender, income, educational attainment, and number of children in a family. This information is critical for assessing the validity of our empirical design.

Second, our data on voter turnout for both national and local elections comes from a project that has scanned and digitized the complete electoral rolls for the 1994 and 2010 elections in Sweden (Lindgren, Oskarsson, and Persson 2019). For these two elections, individual-level voter turnout is available for 90-95 percent of the total electorate. 
Figure 1: Time line

$\underbrace{\begin{array}{c}\text { Citizen } \\ \text { Eligible }\end{array}}_{\text {Treated }} \underbrace{C}_{\text {Controls }} \begin{gathered}\begin{array}{c}\text { Citizen } \\ \text { Non-eligible }\end{array} \\ \begin{array}{c}\text { Non-citizen } \\ \text { Non-eligible }\end{array}\end{gathered}$

\section{Identification strategy and empirical design}

Our main aim in this study is to examine the extent to which the high abstention rates of non-citizens in local elections can be explained by the lower salience of these elections. To do this, we utilize the fact that naturalized immigrants are entitled to vote in the more salient (national) election as well, whereas non-naturalized immigrants are only able to vote in local elections.

A simple comparison of the turnout rates of naturalized and of non-naturalized immigrants will not suffice to answer our research question, since these two groups can be expected to differ in a number of respects that may affect their likelihood of voting. To overcome this problem, we employ a regression discontinuity design (Hahn, Todd, and Van der Klaauw 2001), and we focus on the subset of immigrants who were granted citizenship right around the time of the two elections under study.

The basic set-up of this design is illustrated graphically in Figure 1. The time axis in the diagram denotes the date of citizenship acquisition in relation to the date of the election $(E)$ and the cut-off date for being registered on the electoral rolls $(C)$. Our treatment group consists of those individuals who have acquired their citizenship before $C$, so that they are both citizens and eligible to vote for the national parliament on election day. Our control group comprises the individuals who are granted citizenship between $C$ and $E$ - meaning that, 
although they are citizens on election day, they are not eligible to vote in the national election (because they became citizens after $C$ ). A third group, finally, consists of those persons who acquire their citizenship after election day, and who thus are neither citizens nor eligible to vote for the national parliament on the day of the election. To help disentangle the salience effect from a possible pure citizenship effect, we mainly focus on the two former groups, since this means citizenship is held constant while eligibility is allowed to vary. However, we come back to the third group later in the paper, when we investigate whether gaining citizenship per se while still lacking the right to vote has an impact on voter turnout in local elections.

Consequently, to examine whether immigrants would vote to a greater extent if they were entitled to vote at the national level as well, we compare the local turnout of those labelled Treated with that of those labelled Controls in Figure 1. The logic underlying this approach is straightforward. The exact timing of the citizenship decision is outside the control of the individual, so those who acquire citizenship slightly before the eligibility cut-off date should be identical, in all relevant respects, to those who acquire it slightly after this date. Close to the cut-off date, then, it is as if random whether an individual is a citizen with the right to vote in the national election or a citizen with the right to vote only in local elections. The running variable in our main empirical analysis counts the number of days from the eligibility cut-off date, which was 79 days prior to election day in 1994 and 30 in 2010.

Our sample consists of foreign-born persons who were granted citizenship in 1994 and 2010, respectively. From this group we further exclude all individuals who were citizens of another Nordic country when applying for Swedish 
citizenship. The reason for this is that Nordic citizens have access to a simplified application procedure, which gives them a considerably greater ability to decide when to become Swedish citizens. The final sample includes a bit more than 34,000 individuals in total, of whom 15,179 gained citizenship in 1994 and 18,855 in 2010. In our empirical analysis, we are going analyze the 1994 and the 2010 data separately.

There are two traditional approaches in the RD literature on how to implement the design. The first approach, consists of using all observations and include polynomials of various degrees in order to estimate the discontinuity at the cut-off. The second approach is non-parametric, which focuses on observations close to the cut-off where there is local randomization. In this study we follow the second approach, which has become increasingly standard in the literature, and we specify a local linear regression on each side of the cut-off when zeroing in on the observations close to the eligibility threshold (Hahn, Todd, and Van der Klaauw 2001)

The non-parametric approach to RD estimation involves a trade-off between bias and precision. Theoretically, one would like to zoom in on observations just around the cut-off where there is local randomization. This minimization of the bias, however, comes together with bad precision since one would only use very few observations just around the cut-off. Optimal choices of bandwidths for the running variable in order to balance between bias and precision has as a consequence been presented (Calonico, Cattaneo, and Titiunik 2014a,b; Calonico et al. 2017). In our case, a calculation of a symmetrical MSE-optimal bandwidth for the entire sample yields a bandwidth of 43 days, whereas the MSE-optimal bandwidths are 45 days for 1994 and 42 days for 2010 separately. 
The obstacle in our case, however, is that the institutional setting summarized in Figure 1 puts constraints on the implementation of data-driven (optimal) bandwidths. For the 1994 election, the bandwidth to the right of the cut-off cannot be wider than 79 days, because we would otherwise capture the salience effect and the pure citizenship effect simultaneously. In the case of the 2010 sample, the bandwidth cannot be wider than 30 days to the right of the cut-off, for the same reason. The MSE-optimal bandwidth for 2010 is hence simply too wide. In order to be as transparent as possible, while still acknowledging the institutional constraints, we will display the estimated RD-coefficients for all the possible different bandwidths for each year and treatment window separately in the result section.

In our case, the running variable is expressed in days and hence is discrete. The data will therefore have an inherent grouped structure. Lee and Card (2008) accordingly suggest that standard errors be clustered on the running variable when the running variable is discrete. This procedure has recently drawn criticism in Kolesár and Rothe (2018), who argue that clustering standard errors in that way produces standard errors that actually have worse coverage properties.

Kolesár and Rothe (2018) suggest we instead use smaller bandwidths and stick to heteroskedasticity-robust standard errors when we have enough observations close to the cut-off, or that we use the honest confidence intervals discussed in their paper. In our case we have quite a few observations, meaning we can zoom in on the cut-off. We therefore choose to estimate heteroskedasticity-robust standard errors in the main analysis, but we provide results with alternative confidence intervals as a robustness check in the online Appendix (see figures C5 and C6) Moving on to the identifying conditions, the regression discontinuity design 
Figure 2: Assessing the RD -design: Bunching histograms

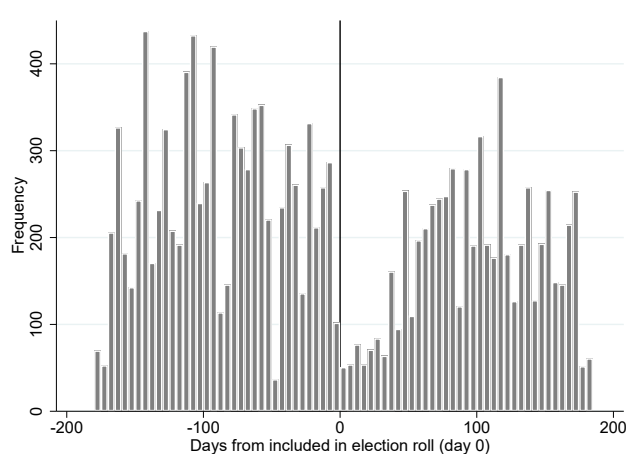

(a) RD bunching histogram, 1994

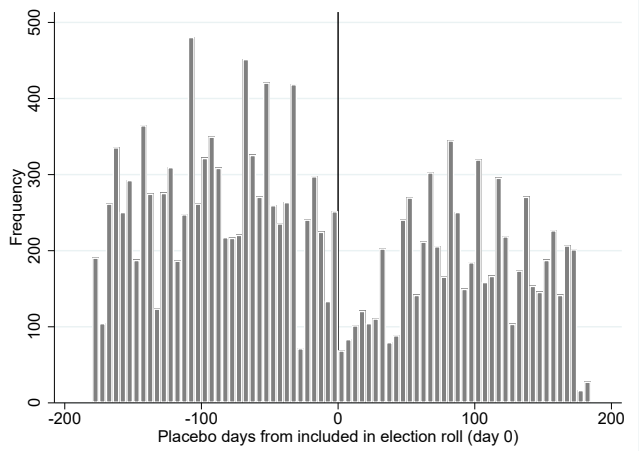

(c) RD bunching histogram, 1995

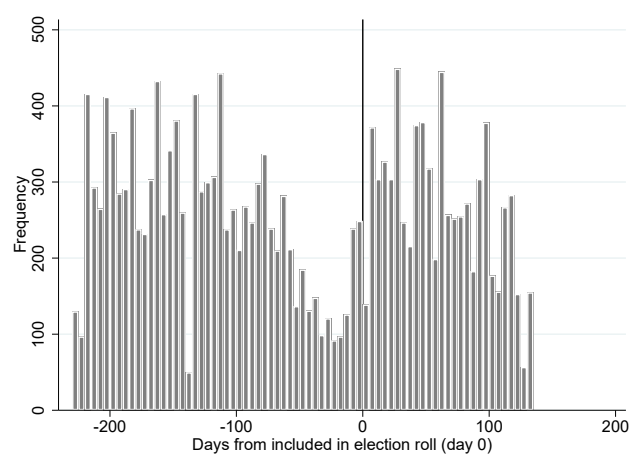

(b) RD bunching histogram, 2010

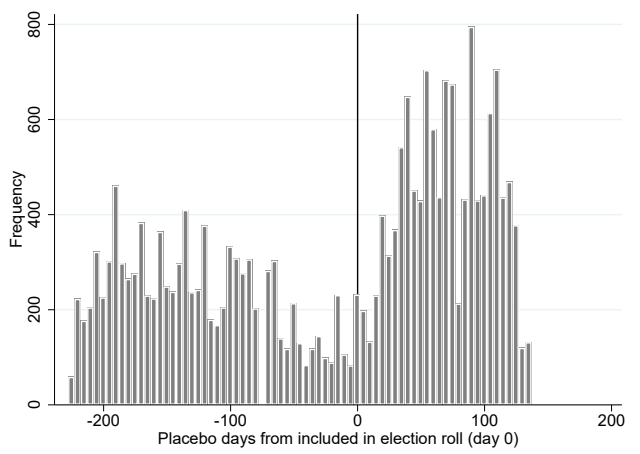

(d) RD bunching histogram, 2011

Notes: Histogram of number of persons granted citizenship around the last day for being registered on the electoral rolls (cut-off). The solid black lines indicate cut-offs.

rests on the premise that the underlying conditional mean function is continuous around the cut-off. This means that, in the absence of any treatment, there will not be any discontinuity around the cut-off. We should therefore observe balance in other observable characteristics, given that the treatment is as if random. Moreover, there should not be any bunching around the cut-off, because such bunching could indicate that individuals can self-select into treatment. One possible scenario would be that people try to become citizens prior to the elections in order to become eligible to vote in the national election. 
One of the strengths of the regression discontinuity design is that the local randomization at the cut-off may be assessed. Figure 2 displays the number of observations for different values of the running variable around the cut-off (which is set to 0) separately for the election years 1994 (Figure 2a) and 2010 (Figure 2b). Overall, the figures do not convey a message of complete balance over the entire period visualized. In the case of 1994, there are particularly few cases decided during the month after the eligibility cut-off. Conversely, in 2010, there are unusually few cases just before the cut-off. These patterns fit neither with a case of no bunching at all nor with a sorting story, which would suggest that alarmingly many persons got processed just before the cut-off both in 1994 and in 2010. We consider the most likely explanation for the results to be found in the extensive Swedish summer vacation, during which activity at any agency is low for several weeks. Note that the time periods with unusually few cases (just after the cut-off in 1994 and before it in 2010) largely overlap with the month of July, during which large segments of public administration in Sweden are less active due to vacation. To support this story further, we provide evidence from two bunching histograms in the years after the elections: 1995 and 2011. No elections took place during those years, which means that no sorting due to eligibility status should happen. Yet, Figure 2c and Figure 2d, show exactly the same patterns as those seen in the election years of 1994 and 2010. Given that the seasonal pattern is the only logical explanation we can think of that would generate the patterns in figures 2a-2d, we do not consider strategic bunching to be an issue in our research design.

We have also assessed balance in observables, thereby further addressing the issue of selection into treatment. We do this by considering age, gender, parenthood, income in $t-1$, years of education, employment status in $t-1$, and 
the probability of living in a large city. We assess this balance both visually and with the aid of regressions. These results can be found in the appendix, with a visual demonstration shown in figures B1 and B2; the results from local linear regressions are seen in Table B1. The overall conclusion is that there are no clear patterns of any discontinuities for these observables. This adds credibility to our claim that no strategic selection of certain individuals into the treatment group is taking place.

Lastly, in Figure 3, we plot voting eligibility in the national election for different values of the running variable. The upper two graphs illustrate the relationship for the full sample. As expected, there is a large difference in voting eligibility on the two sides of the cut-off both in 1994 (the left graph) and in 2010 (the right graph). Among the persons granted citizenship more than a month before the cut-off, all are eligible to vote in the national election; by contrast, hardly any of those granted it after this date are entitled to do so.

As can be seen, however, there is a discernible drop in voting eligibility already prior to the cut-off date in both years. The only reasonable explanation for this drop is that it is due to administrative delay. As noted in the previous section, an individual is only registered on the national electoral rolls after two things have happened: the Migration Agency has informed the Tax Agency of its citizenship decision, and the Tax Agency has recorded this decision in the population registers no later than 30 days prior to election day. According to administrators at the Migration Agency, it usually takes several days for them to inform the Tax Agency (by standard postal mail) of a citizenship decision; and it takes additional time for the Tax Agency to receive the citizenship letter and then to record the date of citizenship in the population registers. Thus, even in cases 
Figure 3: Eligibility by date of citizenship

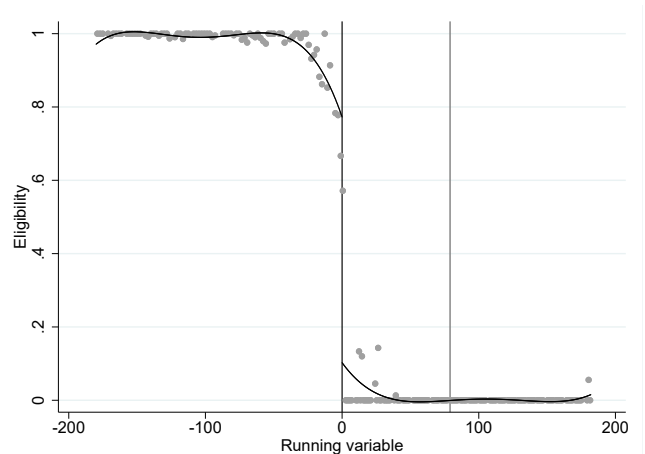

(a) Eligibility, full sample, 1994

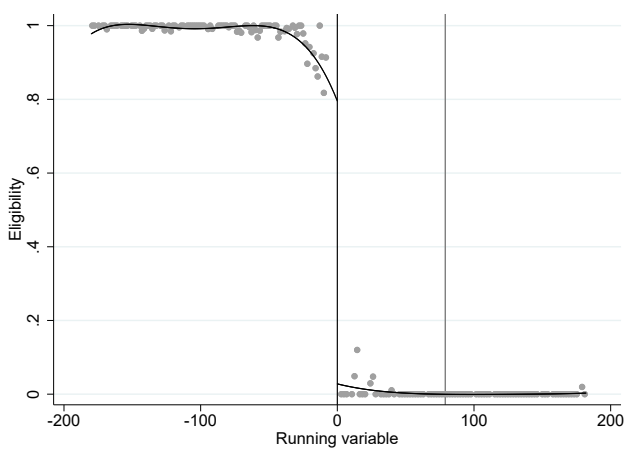

(c) Eligibility, donut sample, 1994

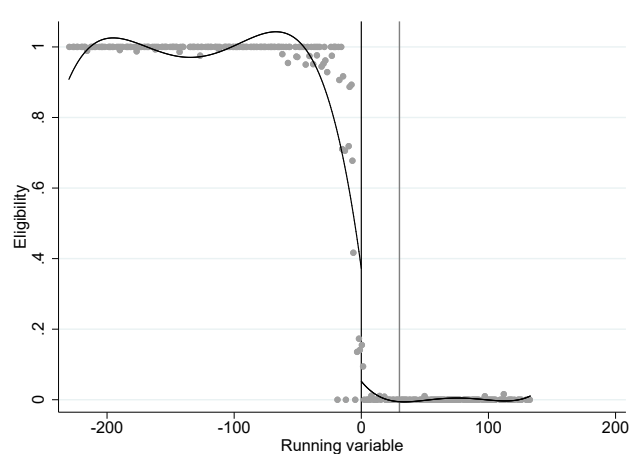

(b) Eligibility, full sample, 2010

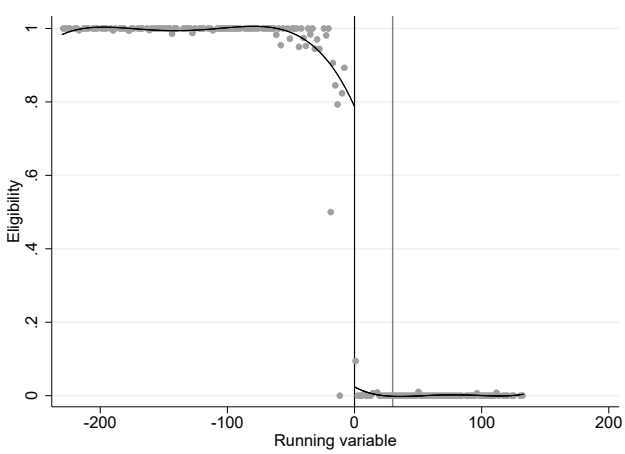

(d) Eligibility, donut sample, 2010

Notes: RD plots according to Calonico, Cattaneo, and Titiunik (2015), with the right to vote in the national election shown on the y axis and the running variable on the $x$-asis.

where the individual is granted Swedish citizenship before the cut-off date, there is no guarantee this information will be recorded in the population registers in time for the individual to become eligible to vote in the national election.

Even in cases where this process goes perfectly smoothly, a citizenship decision must likely be taken at least a week ( 5 working days) before the cut-off date for the information to be recorded in the population registers in time for the individual to be entitled to vote in the upcoming national election. In some cases the delay will be considerably longer. To deal with this problem, we drop all 
individuals who have gained citizenship less than a week before the cut-off date from our analysis. In the regression discontinuity literature, discarding observations close to the cut-off is referred to as the donut approach (Barreca et al. 2011). Our approach differs from the standard donut approach in that we only discard observations on one side of the cut-off.

In the two lower graphs of Figure 3, we show the relationship between national voting eligibility and the running variable when individuals who have gained citizenship the week before the cut-off are discarded. As can be seen, the jump in voting eligibility around the cut-off now becomes much more marked, although there is still a slight tendency for eligibility to drop already in the weeks prior to the cut-off. This is presumably because the administrative process takes more than seven days in many cases.

Finally, as the astute reader may have noticed, there is a handful of individuals who are eligible to vote in the national election even though they became citizens after the cut-off date. We have not been able to find any reasonable explanation for this. However, these observations are so few in number that they should not affect our results. But since compliance at the threshold is not deterministic, we also estimate a fuzzy regression discontinuity model, where we let days from the eligibility cut-off to serve as an instrument for actual eligibility.

\section{Results}

The main results are presented in Figure 4, and concern new citizens in 1994 and 2010 respectively. The $y$-axis in both figures shows voter turnout in the local election, and the $x$-axis displays the date of citizenship (where the date required 
Figure 4: Main RD plots: Effect of eligibility in national elections on voting in local elections

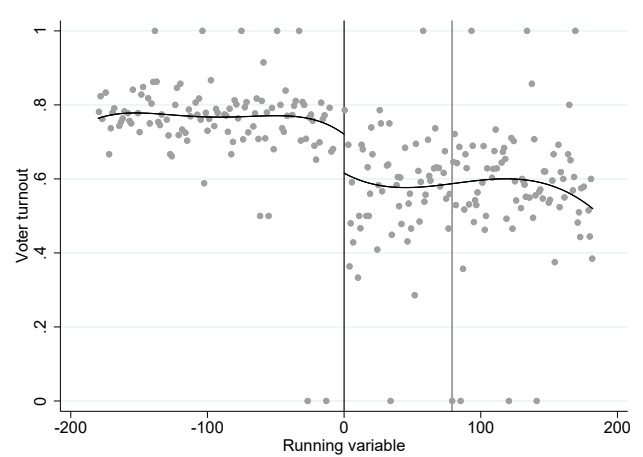

(a) 1994 election

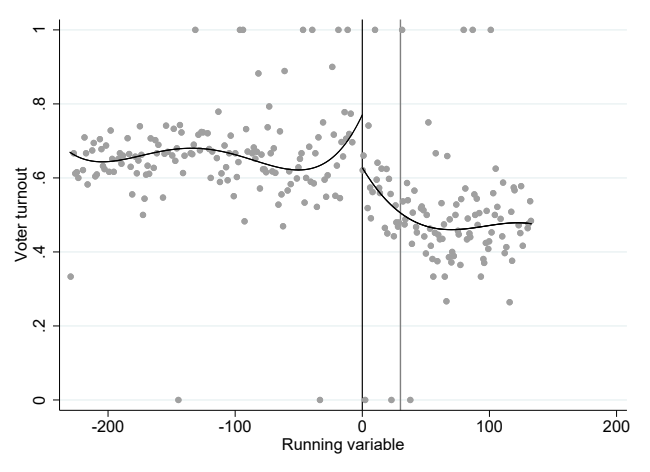

(b) 2010 election

Notes: RD plots according to Calonico, Cattaneo, and Titiunik (2015), using observations from the 1994 (a) and 2010 (b) elections. The dependent variable is turnout in local elections. The running variable measures days before/after the eligibility cut-off. The left-hand side in the plots indicate the treatment window.

for eligibility is normalized to 0). Given that we have previously found that no covariates are discontinuous around the cut-off, the only difference between the naturalized immigrants on either side of the cut-off is voting eligibility in the national election. From the latter premise it also follows that any difference in turnout in the municipal election on the two sides of the cut-off is due to eligibility to vote in the national election. To facilitate for the reader, the treatment period is placed "chronologically" to the left in the RD plots, meaning that these individuals were granted the right to vote in national elections.

The main take-away from these figures is that citizens who are eligible to vote in the national election are much more likely to vote in the municipal election as well. Figure 4 shows that being treated results in an increase in the probability of voting in local elections by approximately 10 percentage points in 2010, and by a somewhat larger amount in 1994. The figures thus suggest a clear effect of voting 
rights in salient national elections on voting in local elections.

Note that, in addition to the main eligibility cut-off, we insert a second cut-off, seen in light grey in both figures. The light grey cut-off shows the actual election date. We insert this in order to provide suggestive evidence against a second story, which concerns the effect of being granted citizenship but not being given the right to vote in the more salient election. While there are some weak indications of a "pure" citizenship effect in 2010, they hinge on inference from a very few individuals. Also, in the case of 1994, we see no indication at all of any citizenship effect. Individuals who gained citizenship just before the election but not in time to be able to vote in the national election voted in as high a proportion in the local election as those who received citizenship after the election. Figure E1 in the Appendix plots the pure citizenship effect as a separate cut-off and we find no indications of a treatment effect in this case either.

The conclusions of these graphical analyses is also backed up by estimation of the discontinuity at the cut-off. For this exercise we estimate local linear regressions, with a uniform kernel. We believe the first choice to be standard in the RD literature, but the latter choice may need some further justification. The logic behind using a triangular kernel is closely related to the core idea of the RD design, which relates to the as-if-random nature of whether a unit gets assigned to either side of a specified cut-off. Furthermore, this should be an increasingly compelling argument as one approaches the cut-off. However, due to the administrative processes at the Migration Agency and the Tax Agency, the uncertainty regarding whether a new citizen actually gains citizenship in time to be eligible increases as we approach the cut-off. Due to this institutional context, the relationship between gaining citizenship before the eligibility date and actually 
being able to vote in the national election is less reliable close to the cut-off. A triangular kernel therefore puts more weight on observations that hold less reliable information. For this reason we apply a uniform kernel, and we also remove all individuals who gained their citizenship less than seven days prior to the relevant eligibility cut-off in our donut RD estimation. In Section C in the appendix, we present estimates using a triangular kernel as a robustness analysis.

Results are seen in Figure 5. The estimations, which are displayed as both sharp and fuzzy, focus only on the salience effect, meaning that we restrict the bandwidth to the salience effect treatment window. Each plot presents the estimated RD coefficients for a range of different bandwidth sizes. This approach is the most transparent way to display the result where one may assess the stability of the estimated coefficients. To make the specifications for 1994 and 2010 as comparable as possible, we consider the range 10 to 79 days for the bandwidth size for both years. ${ }^{5}$ However, there is one important difference between these two analyses: For 1994, the bandwidth is symmetrical (similar on both sides of the cut-off), whereas for 2010, the bandwidth is fixed at 30 days below the cut-off and varies between 10 and 79 days above the cut-off. The reason is, as explained above, that an immigrant needs to receive her citizenship more than 30 days before the general election to be included in the election roll in 2010, whereas it was 79 days in $1994 .^{6}$

For the 1994 election, we observe positive and statistically significant estimates

\footnotetext{
${ }^{5}$ Note that for the smallest bandwidth of 10 days, only three days above the cut-off are included since we use a donut window of seven days.

${ }^{6}$ We display the results for symmetrical bandwidth specifications below 30 days for 2010 in Figure C4 in the Appendix.
} 
Figure 5: Main regression results: Effect of eligibility in national elections on voting in local elections

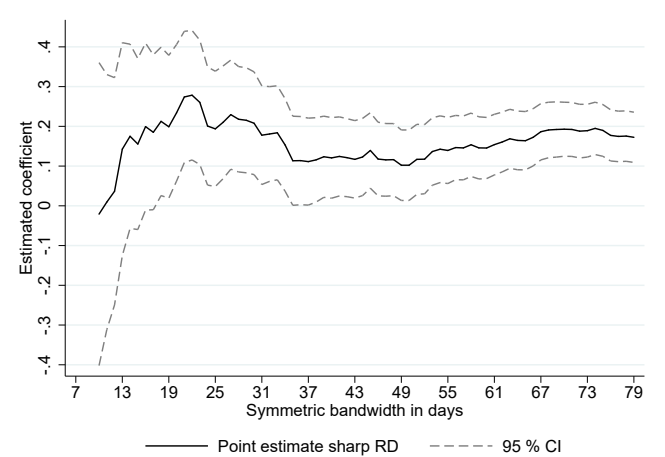

(a) 1994, sharp

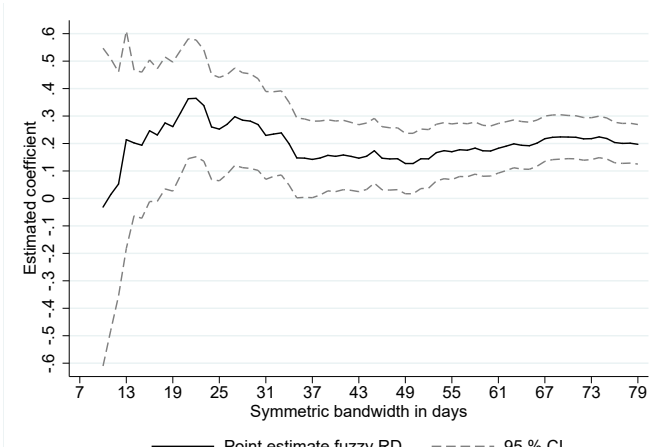

(c) 1994, fuzzy

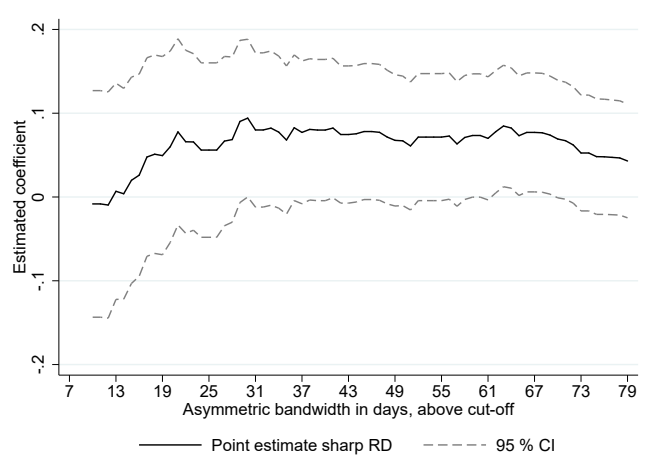

(b) 2010, sharp

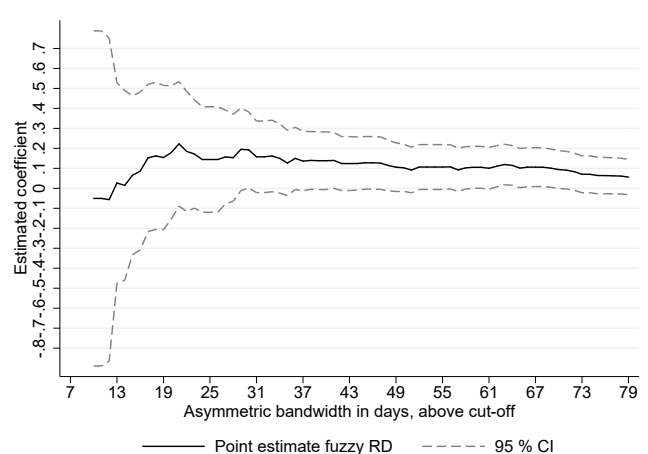

(d) 2010, fuzzy

Notes: Local linear estimations with $95 \%$ confidence intervals, based on conventional standard errors. Estimation with a uniform kernel. Subfigures (a) and (b) display the sharp estimates and subfigures (c) and (d) the fuzzy estimates. The bandwidth for 1994 is symmetrical. The bandwidth for 2010 is asymmetrical and fixed at 30 days below the cut-off, whereas the bandwidth above the cut-off varies for the same range as for 1994. All analyses are run with a donut window of 7 days above the cut-off. The number of observations used when applying the largest bandwidths are 6,031 observations in 1994 and 4,389 observations in 2010.

of at least ten percentage points. This remains true for the fuzzy analysis as well, which as expected provides us generally with somewhat larger estimates. The positive effects are also valid in the case of 2010. While the estimates for 2010 are on average lower than for 1994 and not always statistically significant, the fuzzy 
estimates for 2010 are more similar to those for $1994 .^{7}$

We thus find evidence of a sizable effect of eligibility in national elections on voter turnout in local elections. Whereas our most conservative estimates suggest an effect of around ten percentage points, many specifications suggest the effect could be considerably larger. Judging from the fuzzy estimates, the turnout of non-naturalized immigrants could increase by as much as $20-25$ percentage points if they were allowed to vote in national elections and not just local ones.

To check the robustness of our main findings, we perform a number of sensitivity analyses in Section C in the Appendix. This section presents robustness analysis where we $i$ ) vary the donut window, $i i$ ) use a triangular kernel, iii) change the local polynomial to a quadratic polynomial, iv) run the analysis including covariates, $v$ ) estimations of bias corrected robust confidence intervals and vi) estimations of honest confidence intervals. All these analyses are conducted for different bandwidths just as in the main analysis in Figure 5. Although the estimates vary over different bandwidths, all in all, these appendix results are in line with the conclusions in our main findings, although the quadratic polynomial specification for 2010 casts some doubt on the robustness of the main effect for 2010 .

Moreover, in Section D, we present heterogeneity analyses for our main findings with regards to employment and age. The results do not indicate that the effect of gaining the right to vote in national elections are substantially stronger,

\footnotetext{
${ }^{7}$ One may relate to the calculated optimal bandwidths. For 1994, the symmetrical MSE optimal bandwidth is 45 . For 2010, the data-driven symmetrical MSE optimal bandwidth (42 days) is beyond the salience effect treatment window. A data-driven MSE assymetrical bandwidth above the cut-off for 2010 is 49 days.
} 
or weaker, for these different subgroups. ${ }^{8}$

We discussed the matter of election salience versus becoming a citizen previously when we presented the RD-plots. We have a middle group of individuals that became citizens too close to the election day to be registered on the electoral rolls. These individuals have thus been naturalized without being eligible to vote in the national election. In Section E in the Appendix, we present additional results on the pure citizenship effect, where we compare the individuals in the middle group with those who became citizens after the election day. We find no robust evidence of a pure citizenship effect (i.e. being granted citizenship prior of the election), which provides further evidence that election salience is the main institutional explanation for the gap in voter turnout between natives and immigrants.

\section{On the presumably greater importance of individual characteristics than of eligibility}

The results in Figures 4 and 5 provide evidence of the importance of eligibility in determining levels of political participation. By extension, they provide evidence of the importance of the institutional context as well. Yet, previous studies have made the case that observed differences in political participation between natives and immigrants can be attributed to demographic and socio-economic differences between the two groups (Bevelander and Pendakur 2011; Wass et al. 2015). In view of the results in our study and our access to extensive individual-level

\footnotetext{
${ }^{8}$ In section D, we also present a spill-over analysis for voter turnout among spouses and immigrant from the same country-group of origin living in the same parish who gained citizenship the same year.
} 
data, it is of great interest to analyze the relative importance of individual characteristics and of voting rights in national elections further. We do this by implementing a Oaxaca-Blinder two-fold decomposition, using natives and foreign-born individuals in Sweden (Dancygier et al. 2015).

The method comprise two steps: First, we estimate a pooled linear model for natives and immigrants, using the binary information on voting in local elections as our dependent variable, and a large set of potential predictors as independent variables. Second, using the estimated coefficients, we model the native-immigrant voting gap in an unexplained and an explained part, the latter representing the share of the gap explained by compositional differences between natives and immigrants. The intuition behind the method is to ask the following: given the estimated relationship between voting and our set of individual characteristics, how much higher or lower would immigrants' voting propensity be, conditional on having the same characteristics as natives? ${ }^{9}$

\footnotetext{
${ }^{9}$ For a detailed discussion and description of the Oaxaca-Blinder decomposition, as well as an empirical implementation in Stata (used in this paper), see Jann (2008). The methods originates from Oaxaca (1973) and Blinder (1973)
} 
Table 1: Oaxaca-Blinder decomposition 1994

\begin{tabular}{lcc}
\hline & $(1)$ & $(2)$ \\
& Voted local & Voted local \\
\hline Difference & 0.204 & 0.204 \\
& $(0.000621)$ & $(0.000621)$ \\
\hline Decomposition & & \\
Explained & -0.00462 & 0.119 \\
& $(0.000144)$ & $(0.000491)$ \\
Unexplained & 0.209 & 0.0848 \\
& $(0.000611)$ & $(0.000646)$ \\
\hline Observations & $5,971,600$ & $5,971,600$ \\
Model & twofold & twofold \\
Covariates & Ind. only & + eligible \\
\hline
\end{tabular}

Table 2: Oaxaca-Blinder decomposition 2010

\begin{tabular}{lcc}
\hline & $(1)$ & $(2)$ \\
& Voted local & Voted local \\
\hline Difference & 0.254 & 0.254 \\
& $(0.000494)$ & $(0.000494)$ \\
\hline Decomposition & & \\
Explained & 0.00886 & 0.115 \\
& $(0.000153)$ & $(0.000356)$ \\
Unexplained & 0.245 & 0.139 \\
& $(0.000489)$ & $(0.000531)$ \\
\hline Observations & $7,041,03,8$ & $7,041,038$ \\
Model & twofold & twofold \\
Covariates & Ind. only & + eligible \\
\hline
\end{tabular}

The results from the Oaxaca-Blinder decomposition, using the year 1994 and 2010, are presented in Tables 1 and 2. As suggested by the first row in both tables, the voting gap between natives and immigrants is roughly 20-25 percentage points, of which our analysis suggests small part is accounted for using all of the individual characteristics available in our data. This can be seen by comparing Columns (1) and (2) for the row labeled "Explained" in both tables, where Column (1) only includes individual characteristics whereas Column (2) also include eligibility in the national election. ${ }^{10}$ In other words, the gap is not accounted for using demographic and socio-economic controls solely. When a dummy is added for eligibility to vote in the national election, around half of the gap is closed for both

\footnotetext{
${ }^{10}$ The demographic characteristics include age, age squared, gender, number of children, parental and civilian status, and residence (or not) in one of Sweden's three biggest cities. The socio-economic characteristics are labor income, employment status, and years of education.
} 
years. It appears that having the right to vote in the national election is a much more important contributor to the native-immigrant voting gap than are the individual characteristics of the voters, which speaks to the significance of our main findings.

\section{Conclusions}

Selecting a country's political leaders has traditionally been considered the prerogative of those holding citizenship in a country; accordingly, non-citizen residents have not been allowed to vote. However, rising levels of international migration have made this practice increasingly problematic, since continuing said practice means denying a large and growing share of the population in many established democracies any say over the political development of the country in which they live. In recent decades, accordingly, a number of countries have granted limited voting rights to non-naturalized immigrants, mostly at the municipal or regional level. However, the low turnout in these elections among the immigrants so enfranchised has come as a disappointment to advocates of these reforms (Seidle 2015; Togeby 1999).

One reason suggested in the literature for the low turnout among non-naturalized immigrants is that that they refrain from voting due to the low salience of municipal and regional elections (Hammar 1979; Seidle 2015; Öhrvall 2006). Implicit in this argument is the idea that immigrants would likely become more active politically if, as some scholars propose, they were also given the right to vote in national elections, given the higher stakes that the latter entail (Lenard 2015). 
In this article, we have leveraged high-quality Swedish register data to provide what we believe to be the first systematic empirical test of this "salience hypothesis." Our analyses have yielded strong support for the view that turnout among non-naturalized immigrants would increase were they entitled to vote also at the national level. We have found, namely, that the average likelihood of voting in local elections increases by $10-20$ percentage points once an immigrant gains the right to vote in the national election. By any standard, this effect must be seen as very substantial.

Although this finding is of obvious theoretical and normative importance, the main contribution of the present study is no doubt empirical. A particular strength of this article, we believe, is that it utilizes validated turnout data and it rests on a clear identification strategy. The institutional setting and the data also provided us with opportunities to investigate whether citzenship per se or individual immigrant characteristics can explain the gap in voter turnout, where we found that this was not the case. These advantages make a causal interpretation of the results for election salience considerably more credible.

Admittedly, our analysis also leaves some important questions unanswered. One concerns the generalizability of our findings: i.e., to what extent can the results reported here be translated to other countries and political contexts? Unfortunately, the only way really to answer this question is by replicating our analysis in other countries - which can be rather difficult, of course, since it requires that national and local elections take place at the same time, and that the researchers in question have access to information on voter turnout for a sufficiently large sample of naturalized and non-naturalized immigrants. We see no particular reason, however, to expect the effect to be greater in Sweden than in 
other established democracies. On the contrary, if election salience can be shown to affect turnout among immigrants in Sweden - with its rather liberal citizenship regime and its comparatively high voter turnout - it seems reasonable to assume this will be the case in other countries also.

Another question that warrants more attention in future research concerns the causal mechanisms underlying the observed effect. Based on our analysis we cannot say exactly why it is that immigrants are more likely to exercise their right to vote when they become eligible to vote in the national election. One potential explanation is that granting national as opposed to local voting rights to non-naturalized immigrants affects turnout through its symbolic importance. That is, gaining the right to vote for national government may raise immigrants' sense of belonging to the polity, and thereby increase their likelihood of voting. Alternatively, their increased propensity to vote may reflect a more instrumental motivation: i.e., the higher stakes in national elections may prompt immigrants to seek out more political information and increase their willingness to bear the costs of voting.

These limitations notwithstanding, we believe our results can provide an important impetus for the ongoing debate on voting rights for non-naturalized immigrants. For instance, one possible reaction to the low turnout rates among non-naturalized immigrants in countries where they are entitled to vote is that they show how little value non-citizens attach to the right to vote. The low turnout could then be used to call the desirability of reforms aimed at enfranchising immigrants into question. As our results show, however, the value attached to the right to vote is a direct function of the salience of an election. Non-naturalized immigrants can be expected, therefore, to vote at a much higher 
rate if they can also make their voice heard at the national level, where the political stakes are higher. Instead, then, of interpreting the low turnout of non-naturalized immigrants in local elections as a sign of the insignificance of reforms to enfranchise non-citizens, one could argue on the basis of our findings that these reforms must be made more comprehensive - in order truly to improve the situation of the large and growing population of non-naturalized immigrants found in many established democracies (Lenard 2015; Seidle 2015).

\section{References}

Adman, Per and Per Strömblad. 2000. Resurser för politisk integration: Om de invandrades delaktighet $i$ den svenska demokratin. Integrationsverkets rapportserie 16. Integrationsverket.

Aggeborn, Linuz. 2016. "Voter turnout and the size of government." European Journal of Political Economy 43: 29-40.

Barreca, Alan I., Melanie Guldi, Jason M. Lindo, and Glen R. Waddell. 2011. "Saving Babies? Revisiting the effect of very low birth weight classification." The Quarterly Journal of Economics 126 (4): 2117-2123.

Bevelander, Peter and Ravi Pendakur. 2011. "Voting and Social Inclusion in Sweden." International Migration 49 (4): 67-92.

Bevelander, Pieter. 2015. "Voting Participation of Immigrants in Sweden: A Cohort Analysis of the 2002, 2006 and 2010 Elections." Journal of International Migration and Integration 16 (1): 61-80.

Blais, André. 2000. To vote or not to vote?: The merits and limits of rational choice theory. University of Pittsburgh Press. 
Blinder, Alan S. 1973. "Wage discrimination: Reduced form and structural estimates." Journal of Human Resources 8 (4): 436-455.

Calonico, Sebastian, Matias D Cattaneo, and Rocio Titiunik. 2014a. "Robust data-driven inference in the regression-discontinuity design." The Stata Journal 14 (4): 909-946.

Calonico, Sebastian, Matias D Cattaneo, and Rocio Titiunik. 2014b. "Robust nonparametric confidence intervals for regression-discontinuity designs." Econometrica 82 (6): 2295-2326.

Calonico, Sebastian, Matias D Cattaneo, and Rocio Titiunik. 2015. "Optimal data-driven regression discontinuity plots." Journal of the American Statistical Association 110 (512): 1753-1769.

Calonico, Sebastian, Matias D Cattaneo, Max H Farrell, and Rocio Titiunik. 2017. "rdrobust: Software for regression-discontinuity designs." The Stata Journal 17 (2): $372-404$.

Campbell, David E. 2013. "Social Networks and Political Participation." Annual Review of Political Science 16 (1): 33-48.

Cancela, João and Benny Geys. 2016. "Explaining voter turnout: A meta-analysis of national and subnational elections." Electoral Studies 42: 264-275.

Dancygier, Rafaela M., Karl-Oskar Lindgren, Sven Oskarsson, and Kåre Vernby. 2015. "Why Are Immigrants Underrepresented in Politics? Evidence from Sweden." American Political Science Review 109 (04): 703-724.

De Rooij, Eline A. 2012. "Patterns of Immigrant Political Participation: Explaining Differences in Types of Political Participation between Immigrants and the Majority Population in Western Europe." European Sociological Review 28 (4): 455-481. 
Engdahl, Mattias. 2014. Naturalizations and the Economic and Social Integration of Immigrants. Working paper 2014:11. https://www.ifau.se/sv/Forskning/Publikationer/Workingpapers/2014/Naturalizations-and-the-economic-and-social-integration-of-immigrants/.

Institute for Evaluation of Labour Market and Education Policy (IFAU). Engdahl, Mattias, Karl-Oskar Lindgren, and Olof Rosenqvist. 2020. "The Role of Local Voting Rights for Non-Naturalized Immigrants: A Catalyst for Integration?" International Migration Review, doi : 10.1177/0197918319890256: $1-24$.

Ferris, Dan, Ron Hayduk, Alyscia Richards, Emma Strauss Schubert, and Mary Acri. 2019. "Noncitizen Voting Rights in the Global Era:A Literature Review and Analysis." Journal of International Migration and Integration https : //doi.org/10.1007/s12134-019-00687-8.

Franklin, Mark N. 1996. "Electoral participation". In Comparing democracies: Elections and voting in global perspective, eds. Laurence Leduc, Richard Niemi, and Pippa Norris. SAGE, 216-235.

Franklin, Mark N., Cees van der Eijk, Diana Evans, Michael Fotos, Wolfgang Hirczy de Mino, Michael Marsh, and Bernard Wessels. 2004. Voter Turnout and the Dynamics of Electoral Competition in Established Democracies since 1945. Cambridge University Press.

Garmann, Sebastian. 2016. "Concurrent elections and turnout: Causal estimates from a German quasi-experiment." Journal of Economic Behavior $\mathcal{G}$ Organization 126 (part A): 167-178.

Geys, Benny. 2006. "Explaining voter turnout: A review of aggregate-level research." Electoral Studies 25 (4): 637-663. 
Gidengil, Elisabeth and Dietlind Stolle. 2009. "The Role of Social Networks in Immigrant Women's Political Incorporation." International Migration Review 43 (4): 727-763.

Hahn, Jinyong, Petra Todd, and Wilbert Van der Klaauw. 2001. "Identification and estimation of treatment effects with a regression-discontinuity design." Econometrica 69 (1): 201-209.

Hajnal, Zoltan L. and Paul G. Lewis. 2003. "Municipal institutions and voter turnout in local elections." Urban Affairs Review 38 (5): 645-668.

Hammar, Tomas. 1979. Det första invandrarvalet. Stockholm: Liber.

Heath, Anthony F., Stephen D. Fisher, David Sanders, and Maria Sobolewska. 2011. "Ethnic Heterogeneity in the Social Bases of Voting at the 2010 British General Election." Journal of Elections, Public Opinion $\&$ Parties 21 (2): $255-277$.

Jann, Ben. 2008. "The Blinder-Oaxaca Decomposition for Linear Regression Models." The Stata Journal 8 (4): 453-479.

Kolesár, Michal and Christoph Rothe. 2018. "Inference in regression discontinuity designs with a discrete running variable." American Economic Review 108 (8): $2277-2304$.

Lee, David S and David Card. 2008. "Regression discontinuity inference with specification error." Journal of Econometrics 142 (2): 655-674.

Leininger, Arndt, Lukas Rudolph, and Steffen Zittlau. 2018. "How to Increase Turnout in Low-Salience Elections: Quasi-Experimental Evidence on the Effect of Concurrent Second-Order Elections on Political Participation." Political Science Research and Methods 6 (3): 509-526. 
Lenard, Patti Tamara. 2015. "Residence and the Right to Vote." Journal of International Migration and Integration 16 (1): 119-132.

Lindgren, Karl-Oskar, Sven Oskarsson, and Mikael Persson. 2019. "Enhancing Electoral Equality: Can Education Compensate for Family Background Differences in Voting Participation?" American Political Science Review 113 (1): 108-122.

Migrationsverket. 2020. https://www.migrationsverket.se/Kontaktaoss/Tid-till-beslut.html. Accessed: 2020-03-27.

Oaxaca, Ronald. 1973. "Male-female wage differentials in urban labor markets." International Economic Review 14 (3): 693-709.

Oscarsson, Henrik. 2001. Skilda valdagar och vårval? SOU 2001:65. Regeringskansliet.

Rosenstone, S. and J. Hansen. 1993. Mobilization, Participation, and Democracy in America. New York: Macmillan.

Ruedin, Didier. 2018. "Participation in Local Elections: Why Don't Immigrants Vote More?" Parliamentary Affairs 71 (2): 243-262.

Seidle, F. Leslie. 2015. "Local Voting Rights for Non-Nationals: Experience in Sweden, the Netherlands and Belgium." Journal of International Migration and Integration 16 (1): 27-42.

Togeby, Lise. 1999. "Migrants at the polls: An analysis of immigrant and refugee participation in Danish local elections." Journal of Ethnic and Migration Studies 25 (4): 665-684.

Verba, Sidney and Norman H. Nie. 1972. Participation in America: Political democracy and social equality. University of Chicago Press. 
Verba, Sidney, Kay Lehman Schlozman, Henry Brady, and Norman H. Nie. 1993. "Race, Ethnicity and Political Resources: Participation in the United States." British Journal of Political Science 23 (4): 453-497.

Wass, Hanna, André Blais, Alexandre Morin-Chassé, and Marjukka Weide. 2015. "Engaging Immigrants? Examining the Correlates of Electoral Participation among Voters with Migration Backgrounds." Journal of Elections, Public Opinion and Parties 25 (4): 407-424.

Öhrvall, Richard. 2006. "Invandrade och valdeltagande". In Valets mekanismer, eds. Hanna Bäck and Mikael Gilljam. Liber, 61-76. 


\section{Appendix}

\section{A Replication and data availability}

In this paper, we apply data from Swedish registers. There are several rules and regulations on how to process and store such data. Therefore, we run our empirical analysis through a secured remote desktop system where the data are stored at a server. As a consequence, we cannot make the data available online.

Should a reader wish to gain access to these data in order to replicate our analysis, there are two ways to do so. All of the data we have used are available at Statistics Sweden (SCB) and can be ordered from them (please follow this link: https://www.scb.se/vara-tjanster/bestalla-mikrodata/). Before such a process of ordering data can begin, however, one must seek approval from the Ethical Review Board. All registers are part of Sweden's official statistics, with the exception of data on voter turnout. The latter data have been digitized by the CONPOL Project, and will be deployed at Statistics Sweden. Other researchers will then be able to order these data directly from SCB.

Another possibility would be for a person to become part of our research team temporarily. He or she would then be able to replicate our analysis by using the same remote desktop system with which we have worked. This feasibility of this option depends on where the researcher in question is based, since there are geographical restrictions on data access. If the reader is interested in this option, he or she should contact us beforehand so that we may add him or her temporarily to our research group, whereupon we shall inform the Swedish Ethical Review Board to this effect.

\section{B Balance tests}

Figures B1 and B2 show balance tests, including age, income $(t-1)$, employment $(t-1)$, parental status, years of education, and living (or not) in a major city. The running variable measures days before/after the cut-off. As can be seen, there is no clear jump in any of the covariates at the threshold. We also show the balance using local linear regressions and a uniform kernel. The results, seen in Table B1, demonstrate that almost none of the covariates jump significantly at the eligibility cut-off. 
Figure B1: Balance plots 1

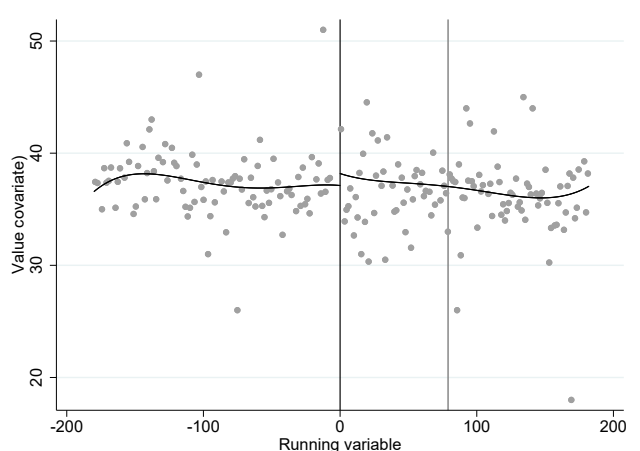

(a) Age, 1994

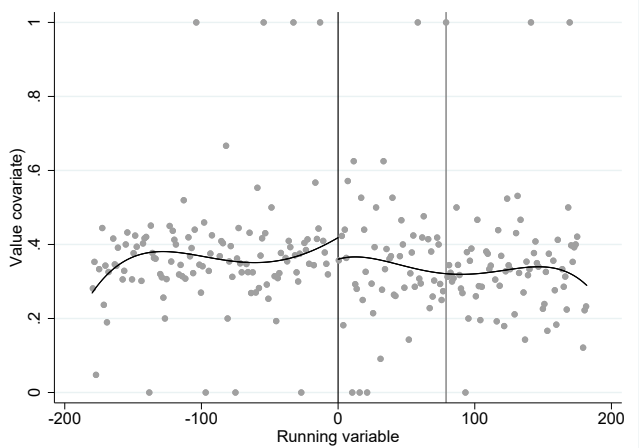

(c) Living in a large city, 1994

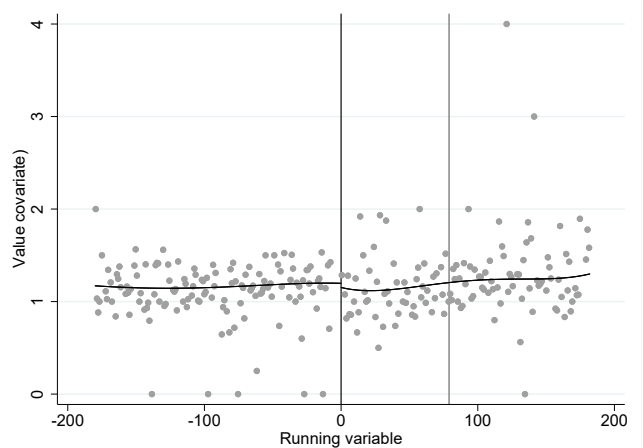

(e) Having children (binary), 1994

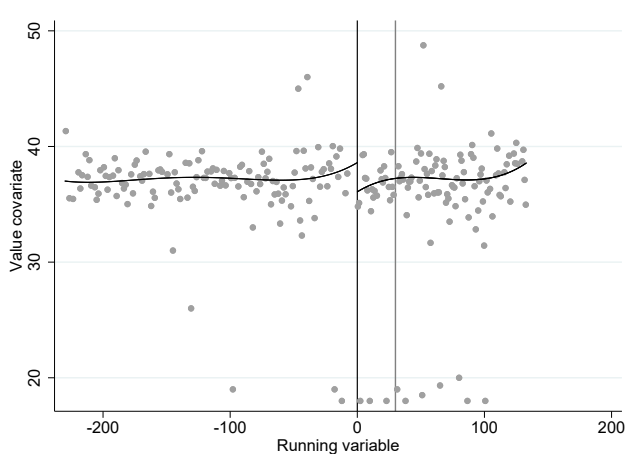

(b) Age, 2010

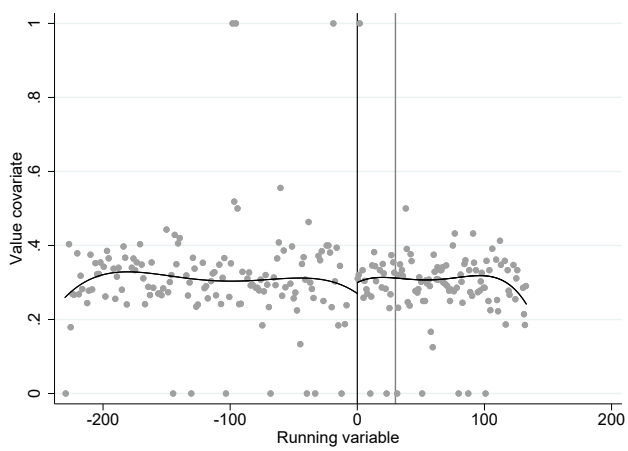

(d) Living in a large city, 2010

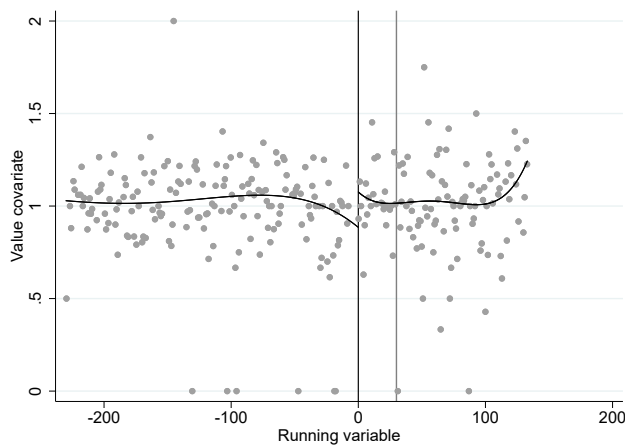

(f) Having children (binary), 2010

Notes: The $x$-axis in the subfigures displays the running variable. The treatment window is placed in a chronological calendar order to the left in each figure. The y-axis displays the outcome. 
Figure B2: Balance plots 2.

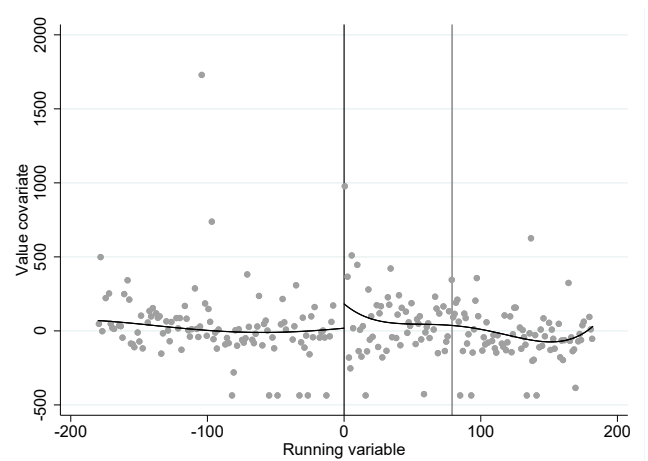

(a) Income t-1, residualized, 1994

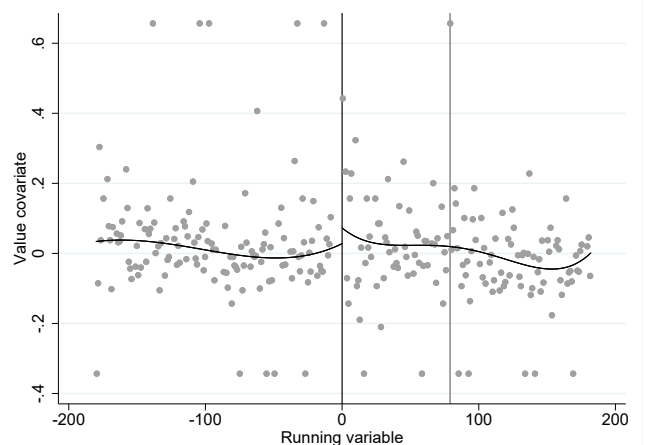

(c) Employment status t-1, residualized,(d) Employment status t-1, residualized, 1994
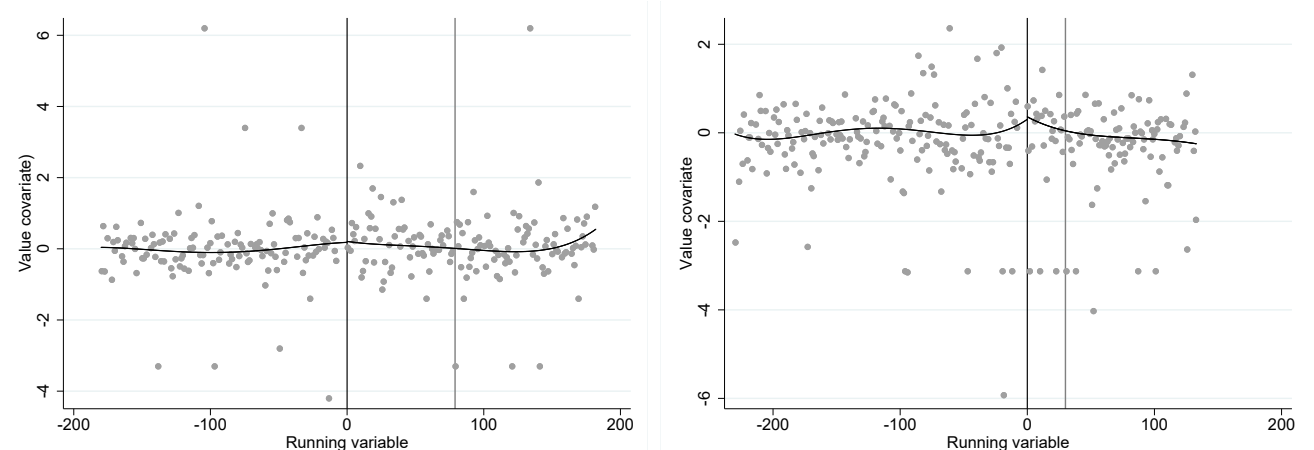

(e) Years of education, residualized, 1994 (f) Years of education, residualized, 2010

Notes: The $x$-axis displays the running variable. The treatment window is placed in a chronological calendar order to the left in each figure. The $\mathrm{y}$-axis displays residuals from a regression where the outcome is regressed on the year of obtained citizenship (1994 and 2010). This is to compensate for a pure year effect (arising from differences in the inflation and the business cycle. (b) Income t-1, residualized, 2010

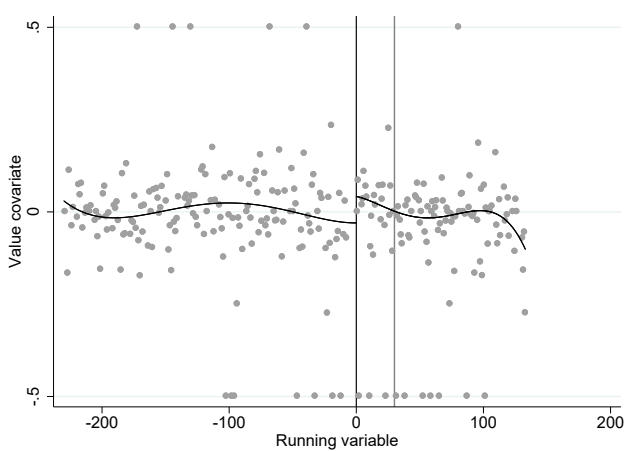

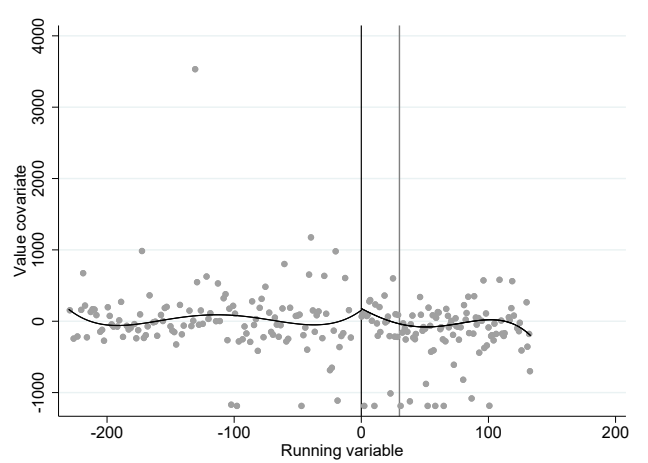


Table B1: Balance table

\begin{tabular}{|c|c|c|c|c|c|c|}
\hline & $\begin{array}{l}\text { Age } \\
(1) \\
\end{array}$ & $\begin{array}{c}\text { Big } \\
\text { City } \\
(2) \\
\end{array}$ & $\begin{array}{c}\text { Parent } \\
(3) \\
\end{array}$ & $\begin{array}{c}\text { Years of } \\
\text { Education } \\
(4)\end{array}$ & $\begin{array}{c}\text { Income } \\
\text { (year prior) } \\
(5)\end{array}$ & $\begin{array}{c}\text { Employment } \\
\text { (year prior) } \\
(6)\end{array}$ \\
\hline \multicolumn{7}{|c|}{ PANEL A: ELECTION YEAR 1994} \\
\hline Bandwidth $79 / 79$ & $\begin{array}{l}-1.345 \\
(0.795)\end{array}$ & $\begin{array}{c}0.017 \\
(0.033)\end{array}$ & $\begin{array}{c}0.154 \\
(0.088)\end{array}$ & $\begin{array}{c}0.021 \\
(0.209)\end{array}$ & $\begin{array}{l}-28.807 \\
(49.025)\end{array}$ & $\begin{array}{l}-0.002 \\
(0.032)\end{array}$ \\
\hline Obs, below cut-off & 2198 & 2200 & 2198 & 2198 & 2200 & 2200 \\
\hline Obs, above cut-off & 3828 & 3831 & 3830 & 3830 & 3828 & 3828 \\
\hline Bandwidth 50/50 & $\begin{array}{l}-0.352 \\
(1.081)\end{array}$ & $\begin{array}{c}0.055 \\
(0.046)\end{array}$ & $\begin{array}{c}0.057 \\
(0.121)\end{array}$ & $\begin{array}{l}-0.059 \\
(0.300)\end{array}$ & $\begin{array}{c}-4.066 \\
(69.067)\end{array}$ & $\begin{array}{c}0.021 \\
(0.045)\end{array}$ \\
\hline Obs, below cut-off & 951 & 951 & 950 & 950 & 951 & 951 \\
\hline Obs, above cut-off & 2078 & 2079 & 2079 & 2079 & 2078 & 2078 \\
\hline Bandwidth $30 / 30$ & $\begin{array}{c}3.508 \\
(1.577)\end{array}$ & $\begin{array}{c}0.035 \\
(0.068)\end{array}$ & $\begin{array}{c}0.211 \\
(0.172)\end{array}$ & $\begin{array}{l}-0.123 \\
(0.444)\end{array}$ & $\begin{array}{c}-25.711 \\
(104.645)\end{array}$ & $\begin{array}{l}-0.000 \\
(0.065)\end{array}$ \\
\hline Obs, below cut-off & 377 & 377 & 377 & 377 & 377 & 377 \\
\hline Obs, above cut-off & 1239 & 1239 & 1239 & 1239 & 1238 & 1238 \\
\hline \multicolumn{7}{|c|}{ PANEL A: ELECTION YEAR 2010} \\
\hline Bandwidth $79 / 30$ & $\begin{array}{c}0.900 \\
(0.817)\end{array}$ & $\begin{array}{c}0.016 \\
(0.033)\end{array}$ & $\begin{array}{l}-0.124 \\
(0.083)\end{array}$ & $\begin{array}{c}-0.191 \\
(0.259)\end{array}$ & $\begin{array}{l}-205.560 \\
(121.530)\end{array}$ & $\begin{array}{c}-0.084 \\
(0.036)\end{array}$ \\
\hline Obs, below cut-off & 1837 & 1837 & 1837 & 1837 & 1833 & 1833 \\
\hline Obs, above cut-off & 2552 & 2552 & 2552 & 2552 & 2549 & 2549 \\
\hline Bandwidth 50/50 & $\begin{array}{c}0.516 \\
(0.930)\end{array}$ & $\begin{array}{c}0.005 \\
(0.038)\end{array}$ & $\begin{array}{l}-0.178 \\
(0.093)\end{array}$ & $\begin{array}{l}-0.009 \\
(0.299)\end{array}$ & $\begin{array}{l}-164.519 \\
(142.199)\end{array}$ & $\begin{array}{l}-0.088 \\
(0.041)\end{array}$ \\
\hline Obs, below cut-off & 1837 & 1837 & 1837 & 1837 & 1833 & 1833 \\
\hline Obs, above cut-off & 1198 & 1198 & 1198 & 1198 & 1195 & 1195 \\
\hline Bandwidth $30 / 30$ & $\begin{array}{c}0.075 \\
(1.117)\end{array}$ & $\begin{array}{l}-0.067 \\
(0.046)\end{array}$ & $\begin{array}{c}-0.084 \\
(0.108)\end{array}$ & $\begin{array}{c}0.287 \\
(0.366)\end{array}$ & $\begin{array}{l}-121.169 \\
(175.313)\end{array}$ & $\begin{array}{l}-0.069 \\
(0.050)\end{array}$ \\
\hline Obs, below cut-off & 1837 & 1837 & 1837 & 1837 & 1833 & 1833 \\
\hline Obs, above cut-off & 635 & 635 & 635 & 635 & 634 & 634 \\
\hline Functional form & Linear & Linear & Linear & Linear & Linear & Linear \\
\hline Kernel & Uniform & Uniform & Uniform & Uniform & Uniform & Uniform \\
\hline Covariates & No & No & No & No & No & No \\
\hline
\end{tabular}

Notes: Standard errors within parentheses. Income, employment, and years of education are residuals from a regression where the outcome is regressed on the year of obtained citizenship in 1994 and 2010. This is to compensate for a pure year effect. 


\section{Robustness analysis for main results}

In this section, we present various robustness checks for our main RD analysis, concerning the effect of having the right to vote in the more salient national election on voter turnout in local elections. To facilitate for the reader,the y-axis in all bandwidth figures in the following sections of the appendix are capped at $(-1,1)$ if necessary. Otherwise, the figures would be pressed together making interpretation of the fluctuation of the point estimate more difficult. This choice implies that in the rare occasions the $95 \%$ confidence interval generates margins above 1 , or below -1 (i.e. larger than 100 percentage points difference), the exact estimate of the upper and lower margins will be missing from the figures. Note that in all these cases, the point estimates are, clearly, not statistically significant different from zero.

In our main analysis in Figure 5, we use a 7-day donut window when we run our regressions. In Figure C1, we check whether our results are sensitive to the specification of the donut window. Specifically, we increase the donut window from 1 to 14 days away from the cut-off. We present the results for both the sharp specification and the fuzzy one. Our conclusion from this robustness check is that our main findings are not particularly sensitive to the specification of the donut window. The estimated coefficients are fairly stable across specifications, although the confidence intervals widens for some donut specifications.

Figures C2 and C3 display the results for various alternative specifications of the main analysis presented in Figure 5. First, we run the same analysis as in the main text, but where we include covariates. Second, we use a triangular kernel instead of a uniform one. Third, we present the results from an analysis with a local quadratic polynomial instead of a local linear specification. The sharp estimates are presented in Figure C2 and the fuzzy estimates in Figure C3.

The point estimates are stable overall in Figure $\mathrm{C} 2$ and Figure $\mathrm{C} 3$. When we shrink the bandwidth to a very small window, the point estimate begins to wobble and the confidence intervals become very wide, which is what we would expect given that we only include 3 days of bandwidth for the smallest specification above the cut-off (10 days bandwidth, removing 7 days in the donut). In general, the results we turn up are in line with our main findings. We estimate in general positive coefficients. These coefficients are often statistically significant although not for all bandwidth specifications (especially not for the 2010 sample).

In the main text, we display the results for bandwidth sizes of 10 to 79 days for the 2010 election. The reason for this is that we want to mimic the 1994 analysis as close as possible to facilitate comparison. However, we cannot increase the bandwidth above the cut-off to more than 30 days for 2010, since this would mean that we also include observations within the citizenship-treatment window. We therefore fix the below cut-off bandwidth to 30 days in Figure 5 in the main 
text. In Figure C4 we display, for completeness and transparency, the results for symmetric bandwidth calculations for the 2010 sample below 30 days of the running variable.

In the main text we also discuss the issue of inference and how to estimate the confidence intervals for our RD coefficients. In short, there is a discussion in the literature on how to perform inference when implementing a non-parametric RD specifications with different polynomials on both sides of the cut-off. Calonico, Cattaneo, and Titiunik (2014b), Calonico, Cattaneo, and Titiunik (2014a) and Calonico et al. (2017) present rdrobust package where they argue that one needs to separate between point estimation and inference when running a non-parametric RD estimation. To overcome this issue, they suggest the estimation of bias-corrected robust confidence intervals. We estimate such confidence intervals in Figure C6. The construction of these confidence intervals are based on an undersmothened point estimate, meaning that the point estimate for a particular bandwidth is not centered within the C.I. In Figure C6, we therefore only plot the bias corrected confidence intervals and not the point estimate. Kolesár and Rothe (2018) and Armstrong and Kolesár (2020) criticize these bias corrected confidence intervals for being too wide. They instead suggest honest confidence intervals. We estimate such confidence intervals in Figure C5. One obstacle when estimating honest C.I.'s is that one need to choose, a piori, a bound of the second derivative of the conditional expectation function at the cut-off. The estimated confidence intervals in Figure C5 assumes a linear approximation with a bound of 0 of the second derivative. 
Figure C1: Robustness analysis for specification of the donut window

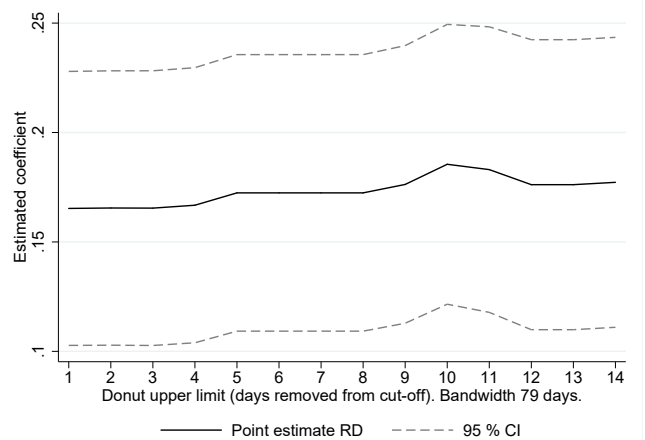

(a) 1994. Sharp estimates

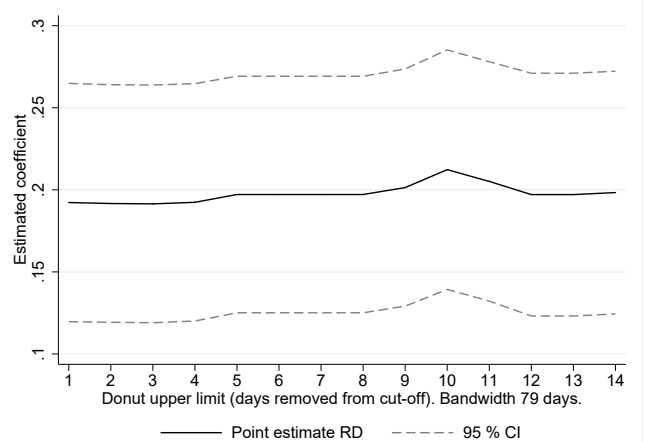

(c) 1994. Fuzzy estimates

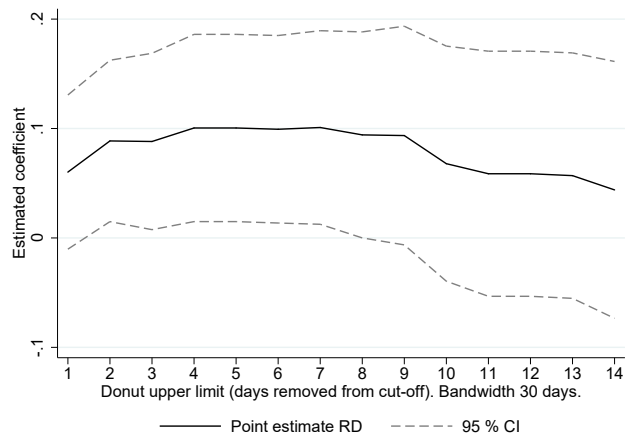

(b) 2010. Sharp estimates

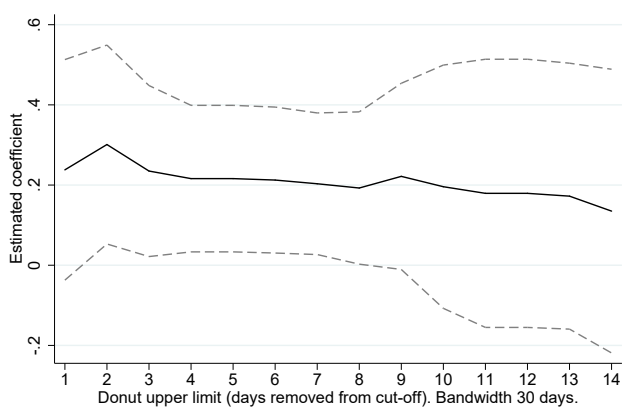

Point estimate RD - - - - . $95 \% \mathrm{Cl}$

(d) 2010. Fuzzy estimates

Notes: The $x$-axis refers to the upper limit of the donut, whereas the lower limit is always set to 0 . The RD estimation is the same as in the main analysis, where we include no covariates and we use a uniform kernel. The bandwidth is 79 days for 1994 and 30 days for 2010 . 
Figure C2: Robustness analysis for covariates, kernels and polynomials. Sharp estimates.

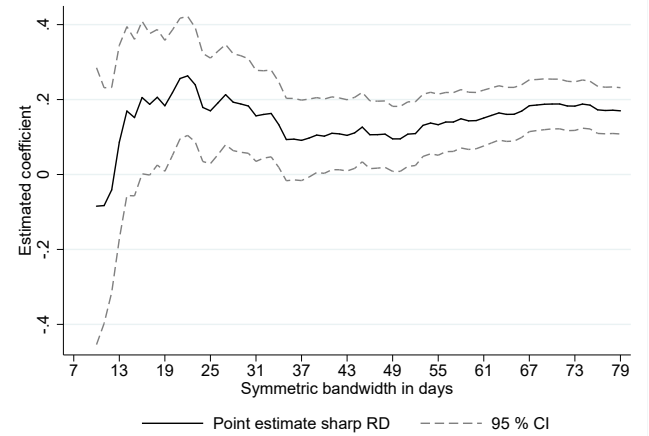

(a) With covariates, 1994

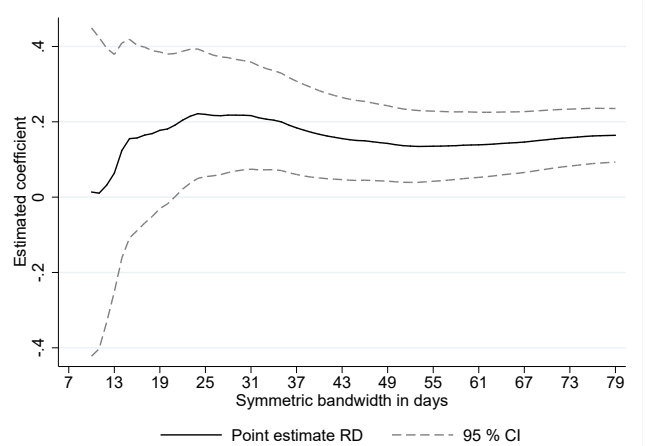

(c) Triangular kernel, 1994

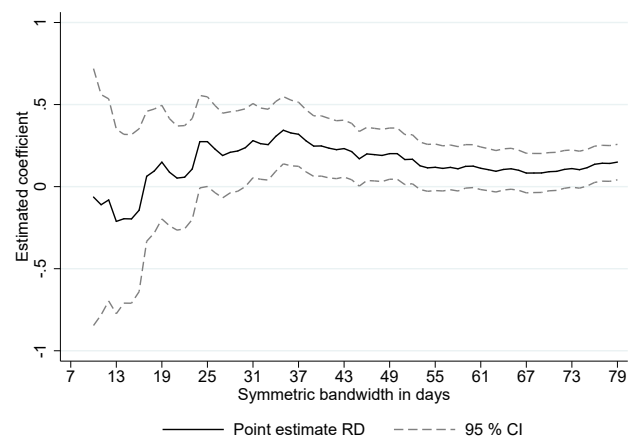

(e) Quadratic polynomial, 1994

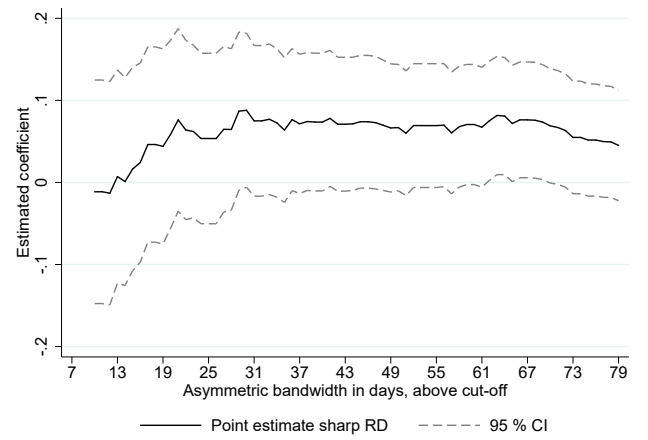

(b) With covariates, 2010

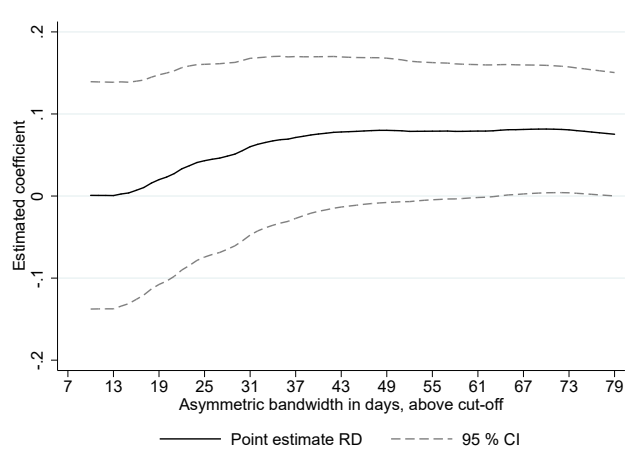

(d) Triangular kernel, 2010

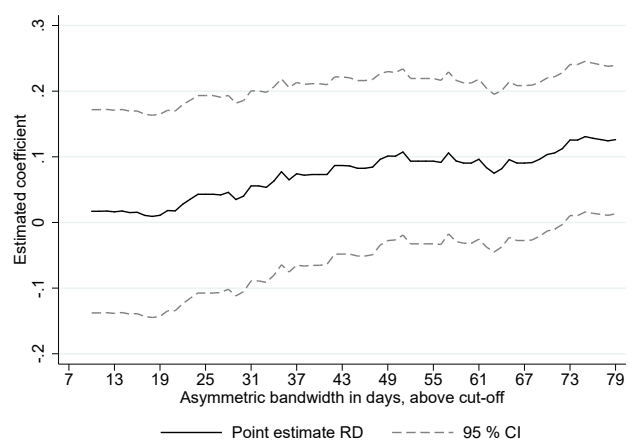

(f) Quadratic polynomial, 2010

Notes: Subfigures (a) and (b) display the main sharp RD estimates but with included covariates. Subfigures (c) and (d) employ a triangular kernel instead of a uniform one. Subfigures (e) and (f) employ a local quadratic polynomial instead of a local linear specification. For 1994 the bandwidth is symmetric. For 2010 it is asymmetric, with the upper limit always set at 30. CI's are capped at $(-1,1)$ 
Figure C3: Robustness analysis for choice of bandwidths, kernels and polynomials. Fuzzy estimates.

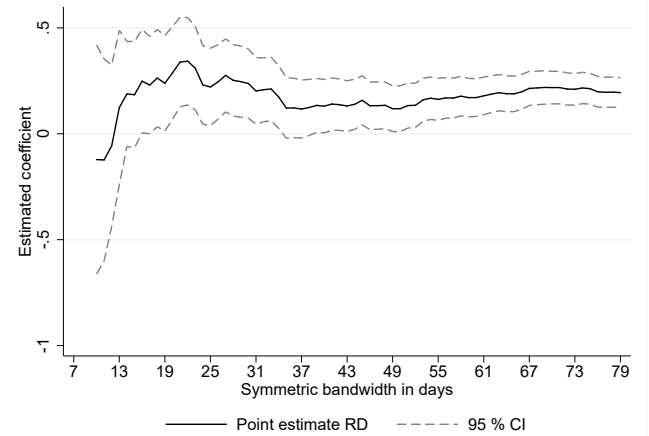

(a) With covariates, 1994

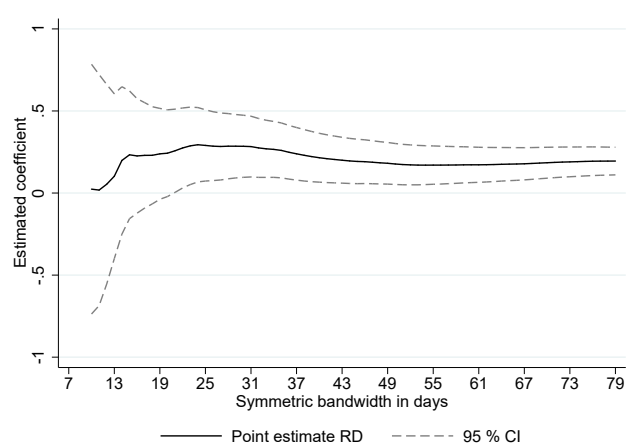

(c) Triangular kernel, 1994

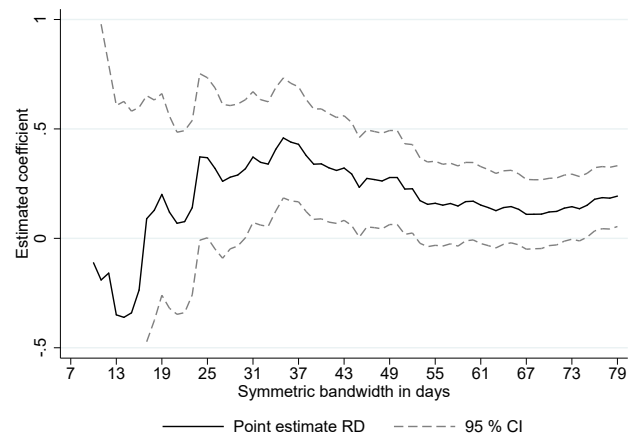

(e) Quadratic polynomial, 1994

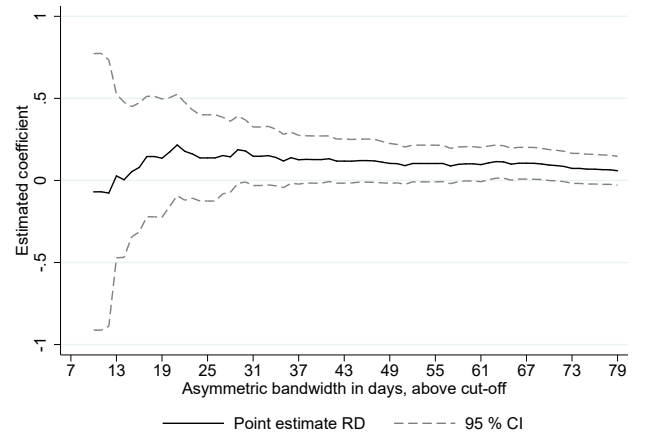

(b) With covariates, 2010

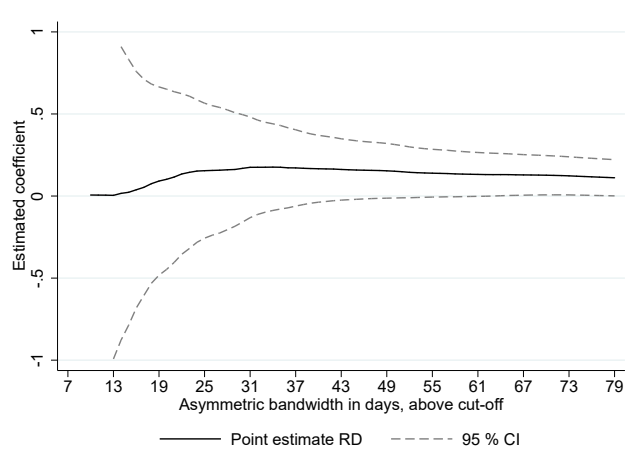

(d) Triangular kernel, 2010

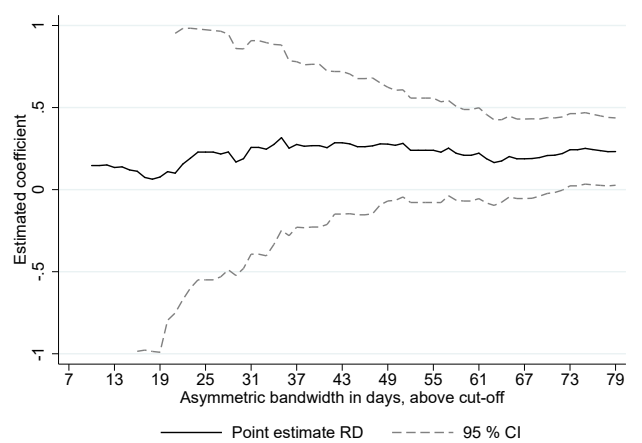

(f) Quadratic polynomial, 2010

Notes: Subfigures (a) and (b) display the main fuzzy RD estimates but with included covariates. Subfigures (c) and (d) employ a triangular kernel instead of a uniform one. Subfigures (e) and (f) employ a local quadratic polynomial instead of a local linear specification. For 1994 the bandwidth is symmetric. For 2010 it is asymmetric, with the upper limit always set at 30. CI's are capped at $(-1,1)$ 
Figure C4: Robustness analysis for small symmetric bandwidths below 30 days. 2010 sample

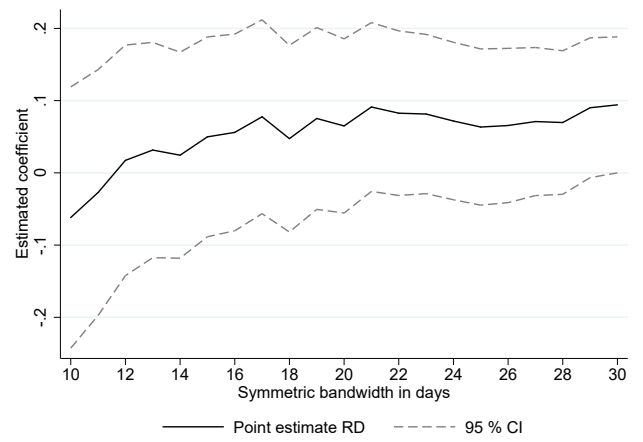

(a) Sharp estimates

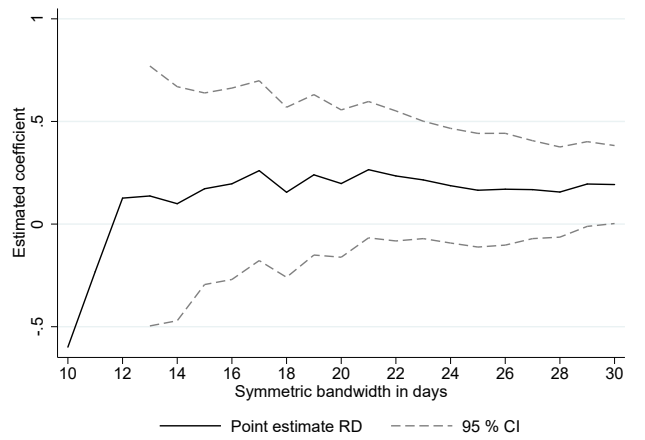

(b) Fuzzy estimates

Notes: The figure displays RD estimates for the 2010 sample with a symmetric bandwidth below 30 days. The RD estimate is the same as in the main analysis, where we include no covariates and we use a uniform kernel. Note that the MSE-optimal bandwidth is above the maximum value of the running variable. CI's are capped at $(-1,1)$ 
Figure C5: "Honest" confidence intervals

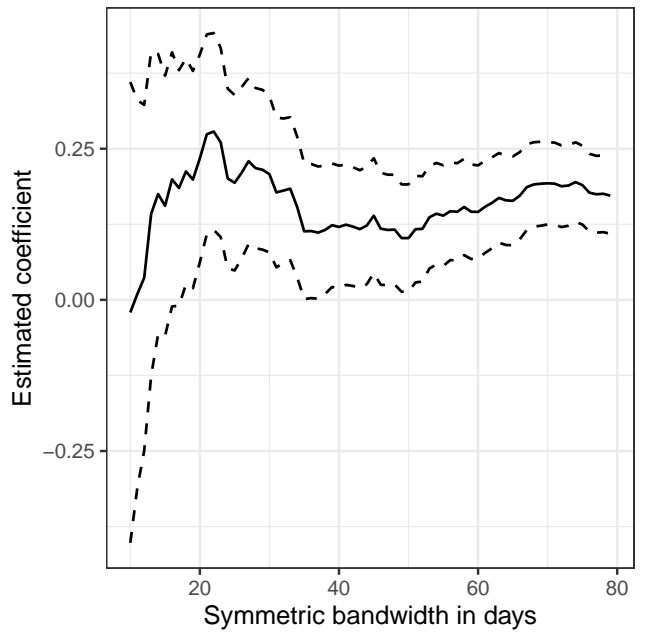

(a) Sharp, 1994

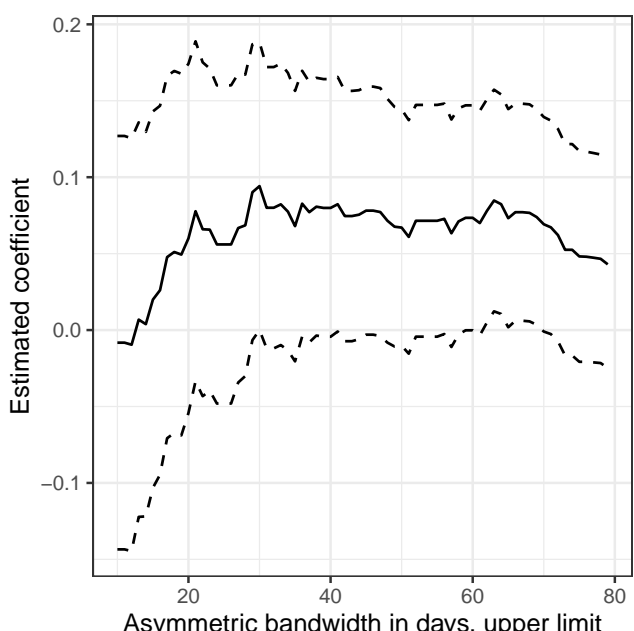

(c) Sharp, 2010

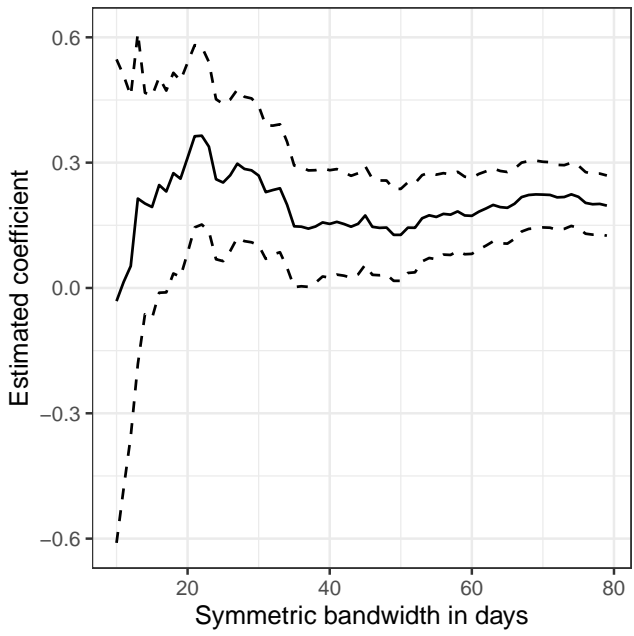

(b) Fuzzy, 1994

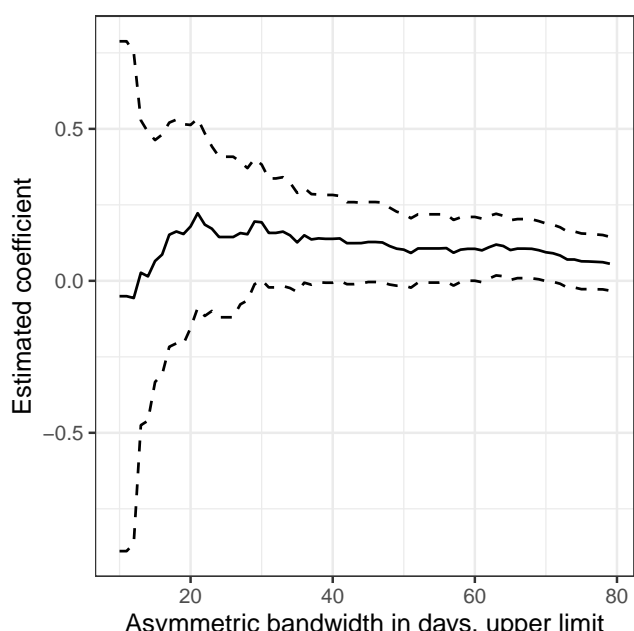

(d) Fuzzy, 2010

Notes: Honest confidence intervals according to Kolesár and Rothe (2018) and Armstrong and Kolesár (2020). The confidence intervals assumes linearity with a bound of the second derivative at 0 . 
Figure C6: Bias corrected robust confidence intervals

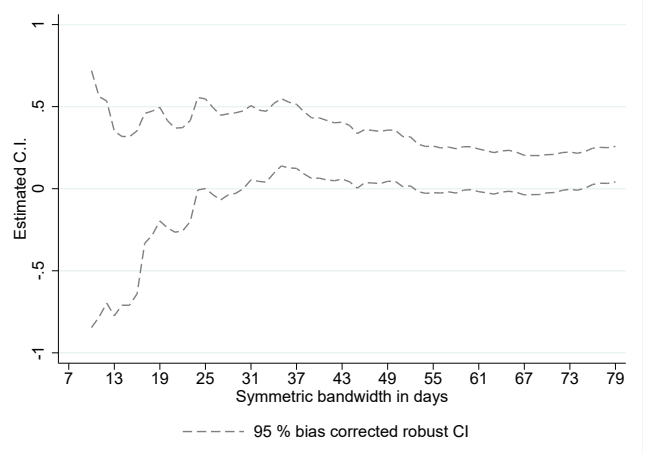

(a) Sharp, 1994

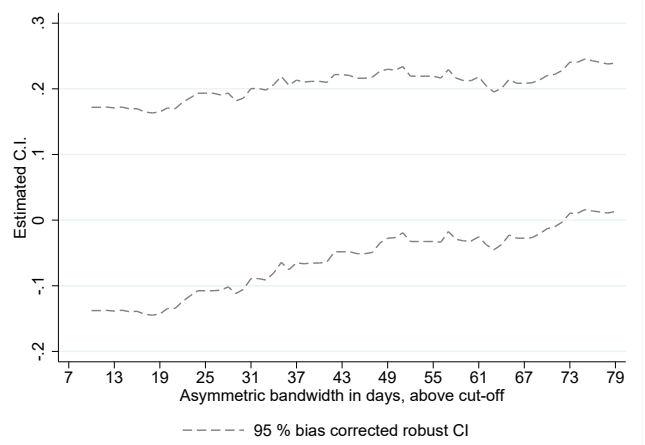

(c) Sharp, 2010

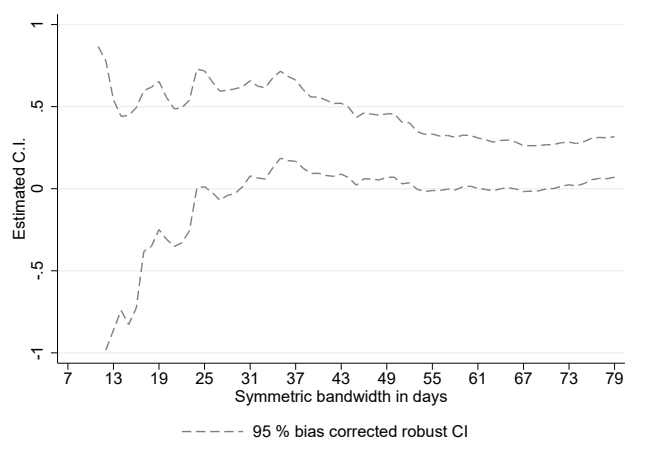

(b) Fuzzy, 1994

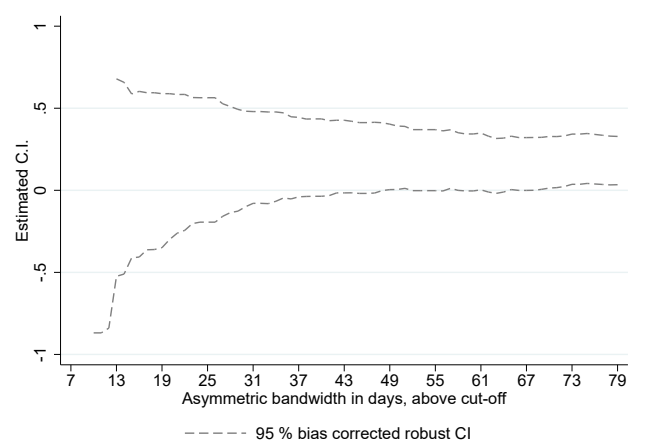

(d) Fuzzy, 2010

Notes: Bias corrected robust confidence intervals according to Calonico, Cattaneo, and Titiunik (2014b), Calonico, Cattaneo, and Titiunik (2014a) and Calonico et al. (2017). Given that the authors of these papers argues for a separation between point estimation and inference and that the point estimates for the bias corrected robust confidence intervals are not centered within the CI's for a given bandwidth, we only plots the CI's in the figure. 


\section{Additional analyses and heterogeneity for main results}

A next natural question is if the main effect is the same for all non-naturalized immigrants, or whether a reform along these lines would instead mobilize particular sub-groups among them. In an attempt to answer this question, we have performed some heterogeneity analyses. To keep these analyses focused, we have decided to examine heterogeneity with respect to two key characteristics: age and socio-economic status (SES).

For the sake of parsimony, we examine the age and SES heterogeneities. For age we divide the sample in two groups: young (all below the age of 30) and old (those aged 30 and above). Socio-economic position is operationalized as whether the individual in question is employed (high SES) or not (low SES). The results are presented in Figure D1 and Figure D2. Given that this is a split-sample analysis with the same underlying total number of observations used in Figure 4, we go straight to the bandwidth graphs for this heterogeneity analysis. Please note that the CI's are capped at $(-1,1)$ just as before in these figures.

The results are less precise here than for our main analysis. This is to be expected, given the few observations of which we now make use. Also, neither the young nor the non-employed seem to be affected to any greater extent than the old and the employed.

Lastly, we run an analysis where we investigate spill-over effects. Given that we have found evidence that eligibility in the national election affects voter turnout in local elections, it will be of interest to see whether this strong individual effect is transmitted to people in close proximity. If we find significant positive effects, then expanding voting rights may have multiplier effects beyond the average effects found thus far. Second, assuming a positive spillover, the main effect in Figure 4 can be interpreted as an information effect, whereby non-naturalized immigrants do not vote due to lack of information. The main effect may, it that case, partly be interpreted as information acquisition at the time of gaining the right to vote in national elections. If that would be the case, it is likely that the effect should be transmitted to others in close proximity.

We investigate this by replacing the outcome variable to voter turnout in local elections among 1) spouses that became citizens in the same year, and 2) immigrants from the same immigrant group who live in the same parish (as the individual in question) who also became citizens in 1994 and 2010, respectively. The results are presented in Figure D3. We find no clear evidence of such spill-over effects. ${ }^{11}$

\footnotetext{
${ }^{11}$ Corresponding bandwidth graphs with regression results are available upon request.
} 
Figure D1: Heterogeneity analysis. Sharp estimates

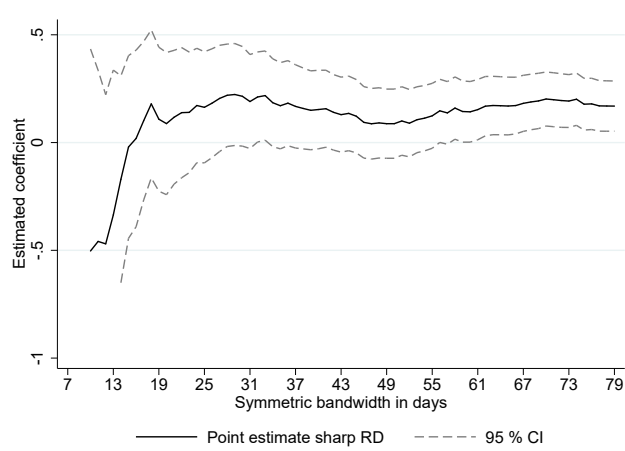

(a) Below 30, 1994

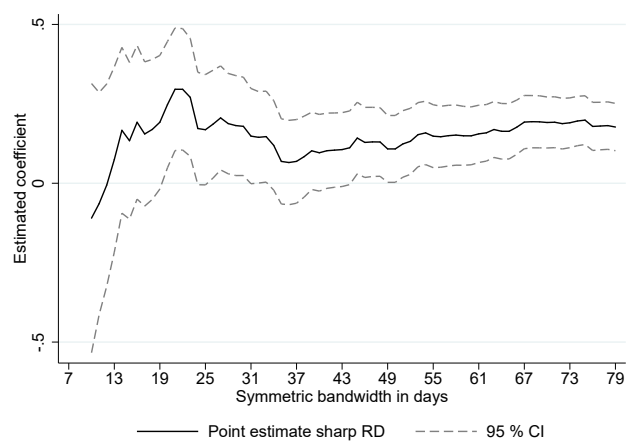

(c) Above 30, 1994

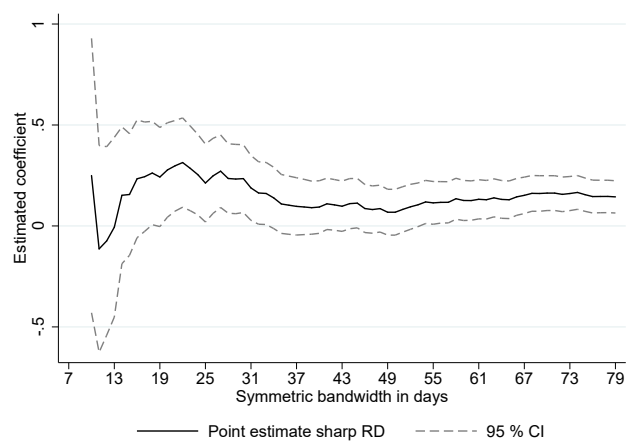

(e) Unemployed, 1994

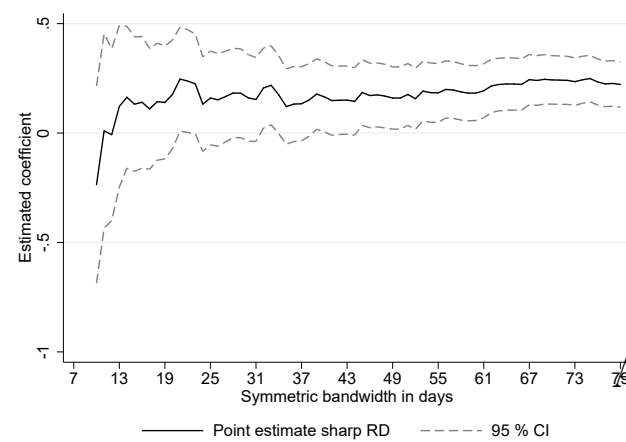

(g) Employed, 1994

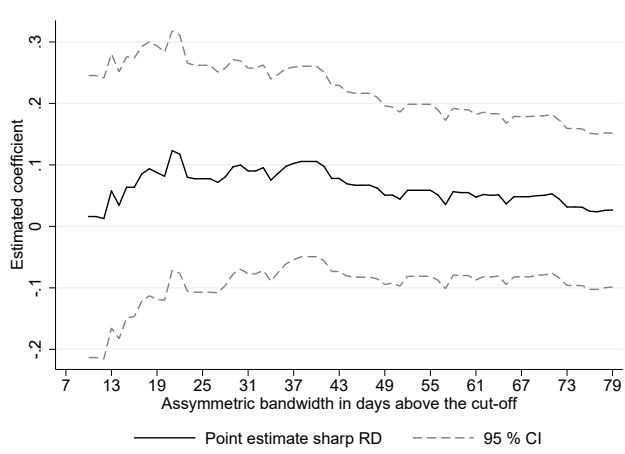

(b) Below 30, 2010

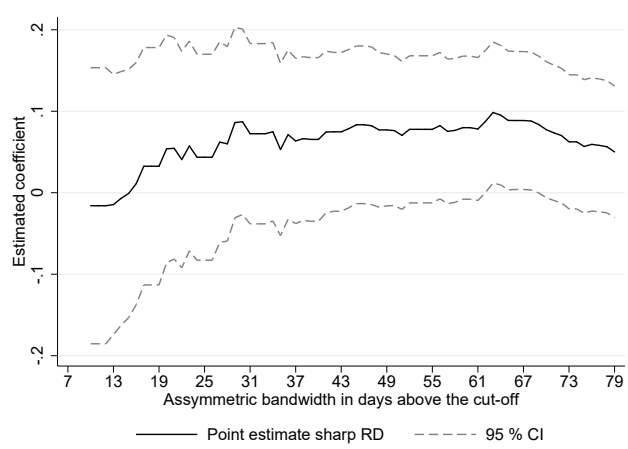

(d) Above 30, 2010

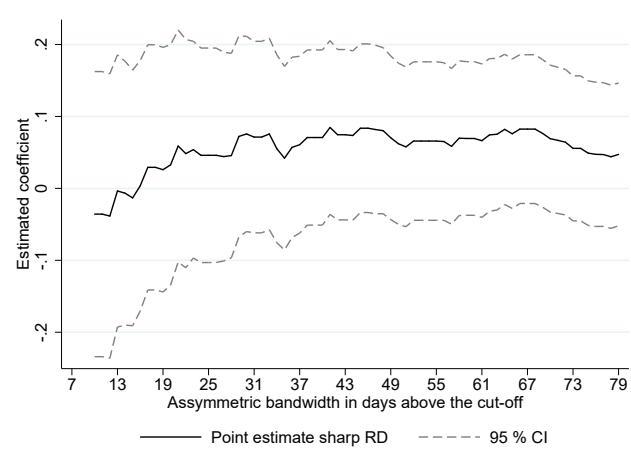

(f) Unemployed, 2010

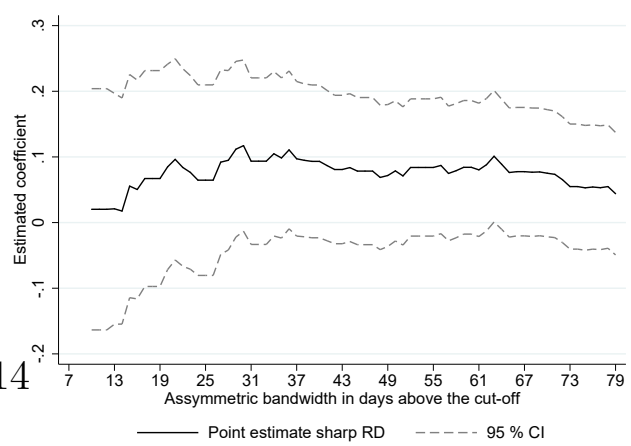

(h) Employed, 2010 
Figure D2: Heterogeneity analysis. Fuzzy estimates

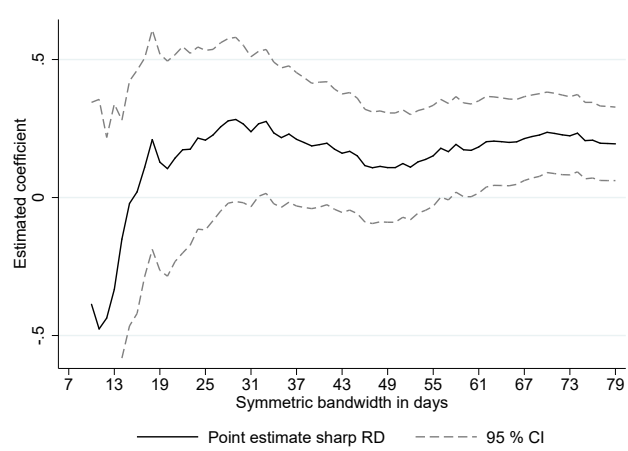

(a) Below 30, 1994

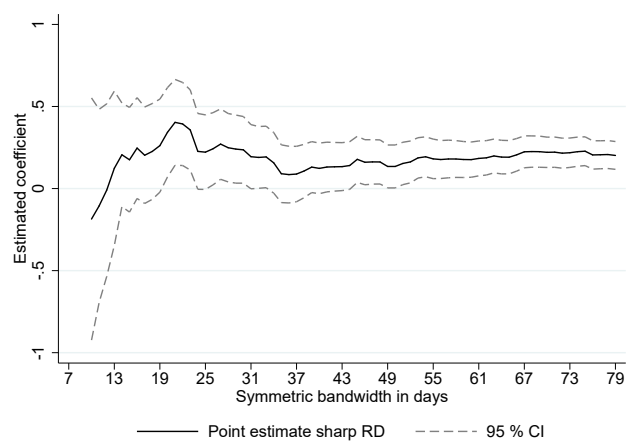

(c) Above 30, 1994

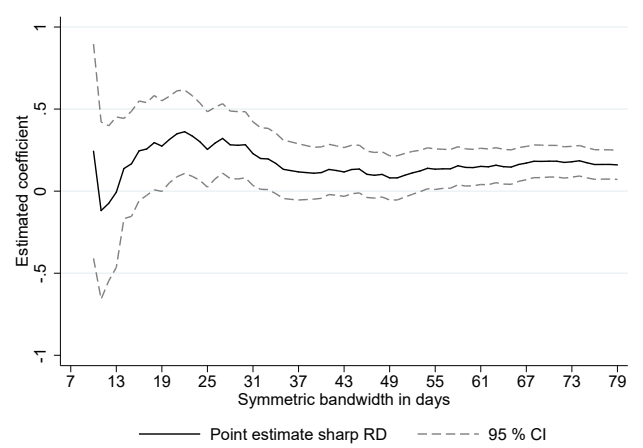

(e) Unemployed, 1994

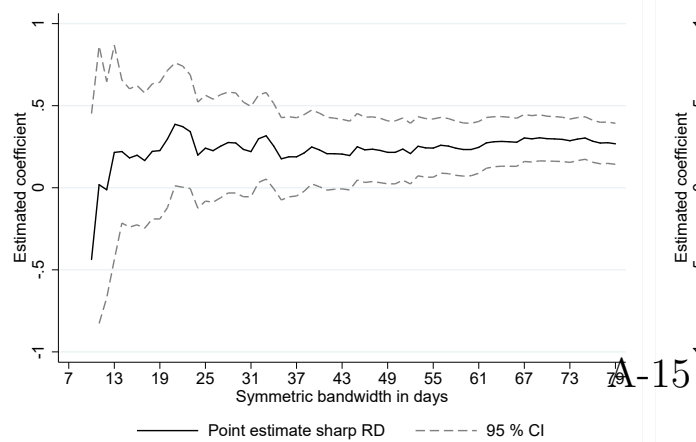

(g) Employed, 1994

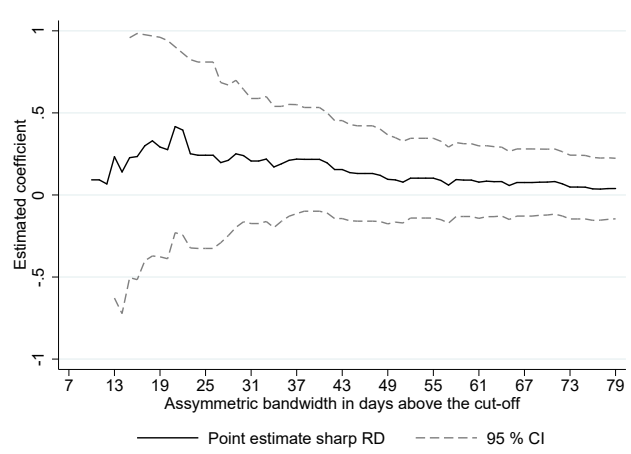

(b) Below 30, 2010

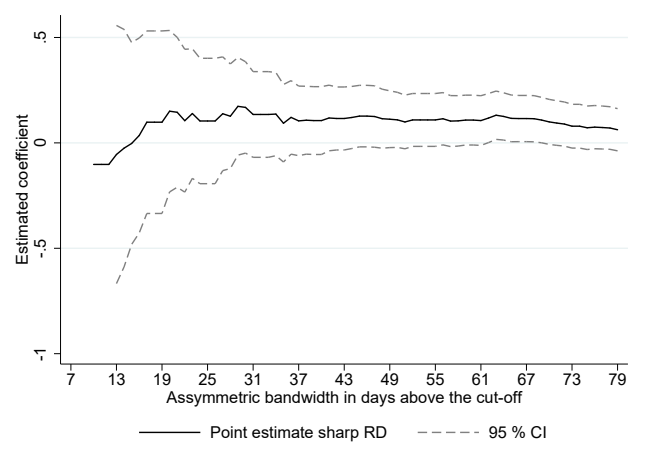

(d) Above 30, 2010

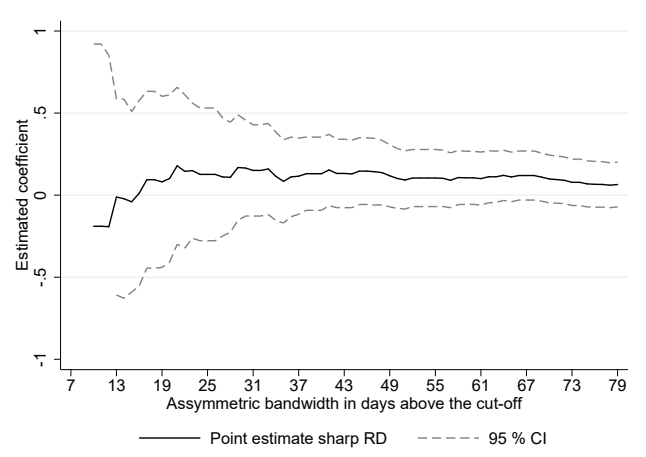

(f) Unemployed, 2010

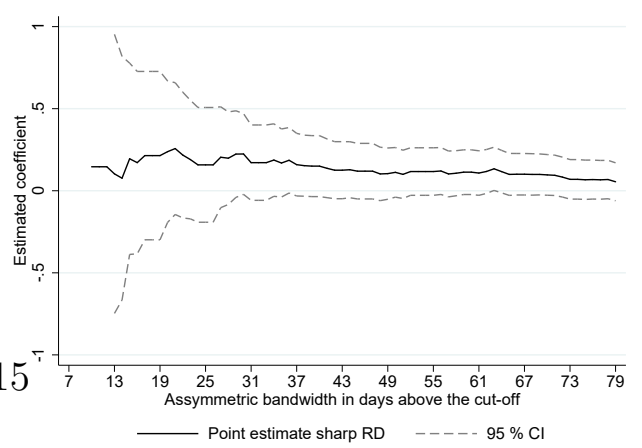

(h) Employed, 2010 
Figure D3: Spill-over effects on spouses and other immigrants

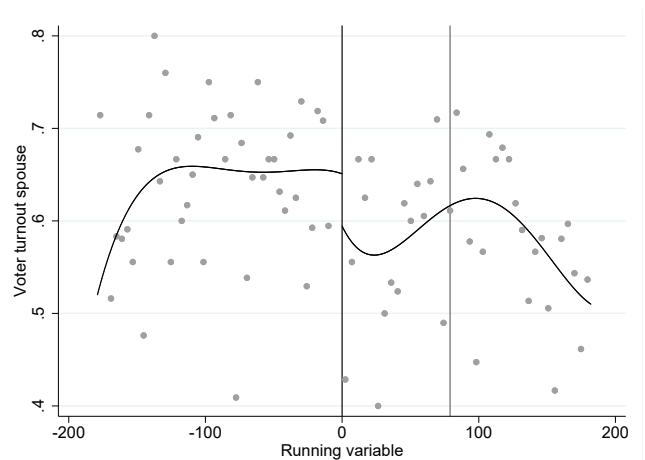

(a) 1994 municipal elections

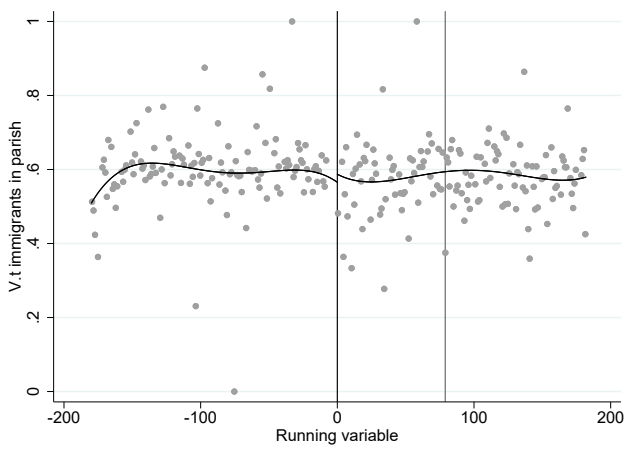

(c) 1994 municipal elections

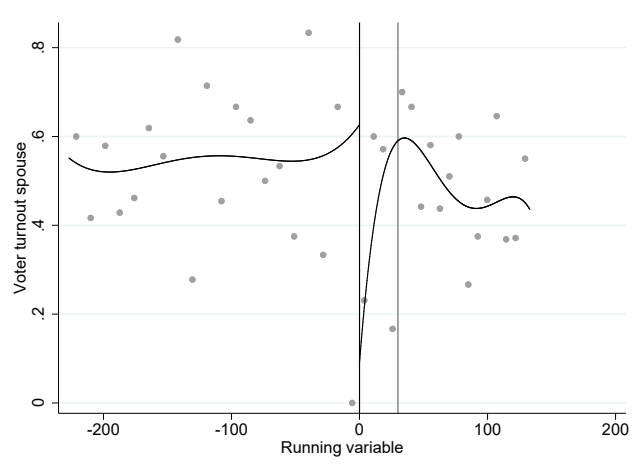

(b) 2010 municipal elections

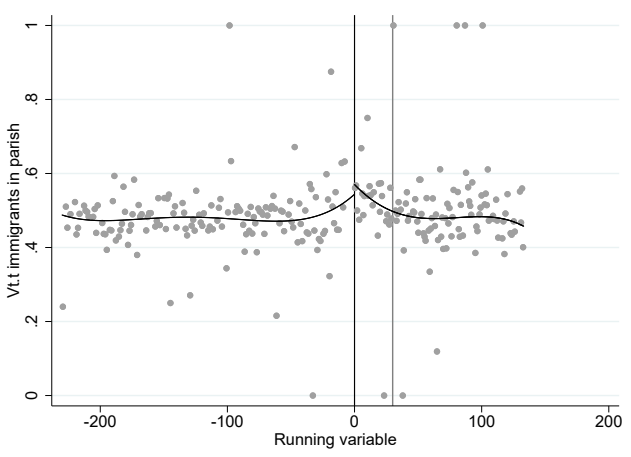

(d) 2010 municipal elections

Notes: RD plots using observations from the 1994 (a) and 2010 (b) elections. The running variable measures days before/after the eligibility cut-off. 


\section{E Analyzing the pure citizen effect}

On several occasions by this point, we have noted that becoming a citizen per se and gaining the right to vote are two different treatments that often go hand in hand. One of the strengths of our article is that we can disentangle these two elements from each other, because we have access to persons who became citizens too close to the election to be registered on the electoral rolls.

In Figure E1 we focus on individuals who gained citizenship prior to the election but too close to it to be registered on the electoral rolls, and compare with those who gained citizenship after the election. We run these regressions with the same donut specification as in our main analysis in Figure 4. One difference is that we do not run a fuzzy specification. The reason for this is that we do not have any variable that we can use, since our only observation is for the date of citizenship. The calculated optimal bandwidths for the pure citizenship treatment are 16 days for the entire sample, and 22 days for 1994 and 23 days for 2010 respectively.

Our conclusion from Figure E1 is that there seems to be no pure citizenship effect. 
Figure E1: The pure citizenship effect

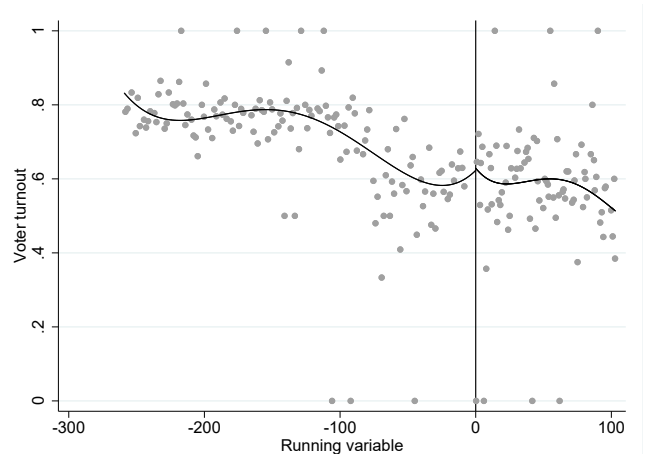

(a) 1994, rd-plot

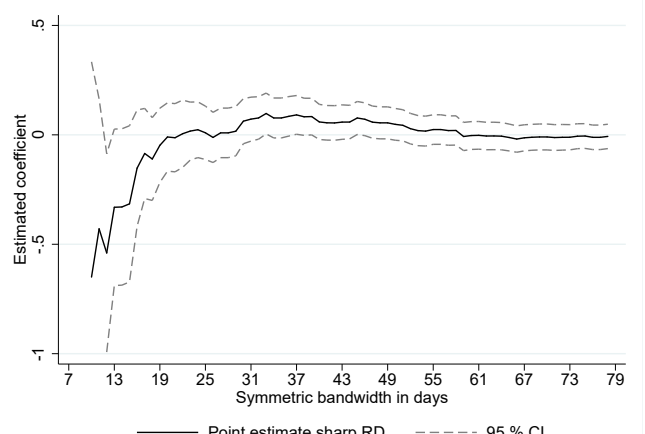

(c) 1994, bandwidth graph

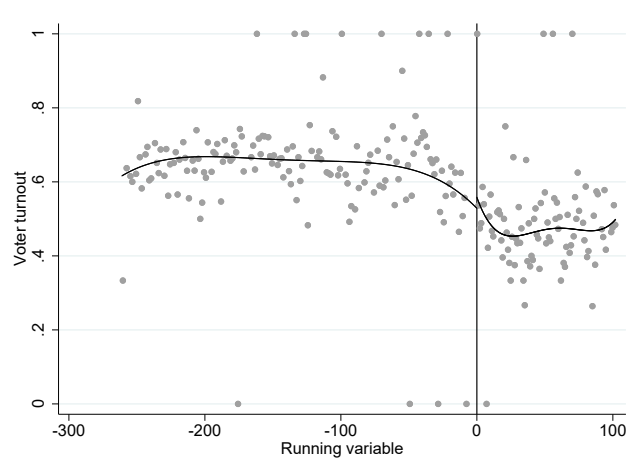

(b) 2010, rd-plot

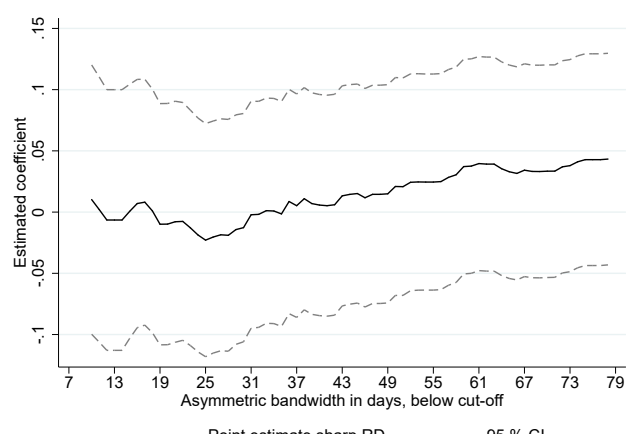

(d) 2010, bandwidth graph

Notes: The RD estimation is the same as in the main analysis, but for a different treatment (pure citizenship effect), where we include no covariates and we use a uniform kernel. in the bottom two figures. CI's are capped at $(-1,1)$

\section{References}

Armstrong, Timothy B and Michal Kolesár. 2020. "Simple and honest confidence intervals in nonparametric regression." Quantitative Economics 11 (1): 1-39.

Calonico, Sebastian, Matias D Cattaneo, and Rocio Titiunik. 2014a. "Robust data-driven inference in the regression-discontinuity design." The Stata Journal 14 (4): 909-946.

Calonico, Sebastian, Matias D Cattaneo, and Rocio Titiunik. 2014b. "Robust nonparametric confidence intervals for regression-discontinuity designs." Econometrica 82 (6): 2295-2326. 
Calonico, Sebastian, Matias D Cattaneo, Max H Farrell, and Rocio Titiunik. 2017. "rdrobust: Software for regression-discontinuity designs." The Stata Journal 17 (2): 372-404.

Kolesár, Michal and Christoph Rothe. 2018. "Inference in regression discontinuity designs with a discrete running variable." American Economic Review 108 (8): $2277-2304$. 